\title{
Jean-Jacques Rousseau oder die Erfindung des modernen Subjekts
}

Nicht allein die Figurenkonstellationen in Friedrich des Großen Libretto, sondern auch die Figuren der Oper selbst besaßen etwas Statisches, Fixiertes, Unwandelbares; sie verkörperten eher Typen als Subjekte in einem modernen Sinne. Dies sollte uns nicht verwundern, da sie im Grunde eher bestimmte philosophische beziehungsweise machtpolitische Positionen, ja mehr noch Figuren innerhalb einer figuralen Deutung von Geschichte, als Personen mit einer humanen Tiefenschärfe darstellten. Um die Mitte des 18. Jahrhunderts aber ergaben sich literarische und philosophische Entwicklungen, die just diese psychologische Tiefenschärfe entfalteten, welche für die Entstehung des modernen Subjekts von so zentraler Bedeutung sind.

Diese Entwicklungen verbinden sich mit einem Namen: Jean-Jacques Rousseau. Ich habe Ihnen diesen aus Genf stammenden Schriftsteller und Philosophen bereits in meiner Vorlesung über die Romantik zwischen zwei Welten ${ }^{1}$ ausführlich vorgestellt, da er für die Sattelzeit von Empfindsamkeit und Romantik von überragender Bedeutung war. Doch ich kann auf Grund seiner zentralen Funktion für das 18. Jahrhundert nicht darauf verzichten, ihn an mehreren Stellen in den Ablauf unserer Vorlesung nun mit veränderter Themenstellung einzubauen. Denn beim Studium der Schriften von Jean-Jacques Rousseau lässt sich die Entstehung, ja die Erfindung des modernen Subjekts gleichsam in Zeitlupe mitverfolgen, eine Entwicklung, die - wie wir schon im ersten Teil unserer Vorlesung sahen - nicht nur für die philosophische, literarische oder literarhistorische Progression, sondern für die Grundlegung der abendländischen Moderne von entscheidender Bedeutung ist. Im Übrigen waren wir schon mehrfach auf den von ihm kreierten Neologismus der ,Perfektibilität' gestoßen. Beschäftigen wir uns aber zunächst mit einigen Biographemen des berühmten „Citoyen de Genève“.

Wollte man Rousseaus Leben mit einem Satz überschreiben, so müsste man vor allem sagen, dass er - in Abwandlung von Roland Barthes' Sentenz über Voltaire - sicherlich nicht der letzte der glücklichen Schriftsteller war. Gewiss, der Genfer Bürger wurde von seinen Anhängern geliebt und in den Himmel gehoben, aber zu Lebzeiten erfuhr der Schriftsteller und Philosoph nicht nur viel Widerstand und Kritik, sondern Häme, Spott und Erniedrigungen. Als er sich ins Schweizer Val de Travers zurückzog, machte man Jagd auf ihn und versuchte, dieses Gottlosen habhaft zu werden oder ihn zumindest außer Landes

1 Vgl. Ette, Ottmar: Romantik zwischen zwei Welten, S. $489 \mathrm{ff}$. u. $590 \mathrm{ff}$.

Ә Open Access. (C) 2021 Ottmar Ette, publiziert von De Gruyter. (c) BY-NC-ND Dieses Werk ist lizenziert unter einer Creative Commons Namensnennung - Nicht-kommerziell - Keine Bearbeitung 4.0 International Lizenz. https://doi.org/10.1515/9783110703467-012 
zu treiben, so dass sich Rousseau auf nahe gelegenes preußisches Gebiet zurückziehen musste und auf der Halbinsel von Saint-Pierre die Rêveries du promeneur solitaire schrieb, eines seiner sicherlich schönsten literarischen Werke.

Doch es war keineswegs nur die Tatsache, dass er von vielen der französischen Aufklärungsphilosophen einschließlich Voltaire mit Hohn und Spott verfolgt wurde, was einen davon überzeugen könnte, in Rousseau den ersten der unglücklichen Schriftsteller zu sehen. In der Auseinandersetzung mit einem Ich, auf das wir gleich mit Blick auf seine Bekenntnisse zurückkommen werden, entfaltete er all jene Spaltungen, die für das Subjekt in der Moderne charakteristisch sind und nach Rousseaus Tod die Schriftstellerinnen und Schriftsteller der Romantik prägten. Doch wir sollten uns davor hüten, den Rousseauismus mit Rousseau zu verwechseln.

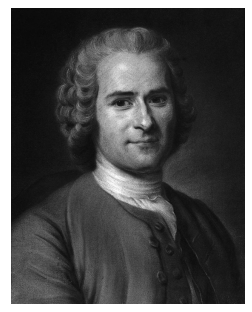

Abb. 32: Maurice Quentin de La Tour: Jean-Jacques Rousseau (1712-1778).

Der Bürger Rousseau wurde 1712 als Sohn eines protestantischen Uhrmachers in der Stadt Genf geboren. Seine Mutter verstarb bei der Geburt, und dieses Ereignis hat den Philosophen stark geprägt, schwebte so doch über seinem gesamten Leben der Schleier eines Todes, der mit seiner eigenen Geburt in eins fiel. Der alte Rousseau erblickte in diesem Faktum zweifellos ein Zeichen, das nicht nur sein Verhältnis zu Frauen und seine sexuellen Erfahrungen mit dem weiblichen Geschlecht, sondern sein ganzes weiteres Leben prägen sollte.

Nach einer Zeit als Lehrling in einer Kanzlei und bei einem Graveur verließ er 1728 seine Heimatstadt und lernte im nahe gelegenen Annecy Madame de Warens kennen, die den Bürgersohn dazu bewegte, zum Katholizismus überzutreten. Madame de Warens war für Rousseau nicht nur in erotischen Dingen von großer Wichtigkeit - manche ihrer Züge hat er später in seinem Roman Julie ou la Nouvelle Héloïse verarbeitet, einem Bestseller der „Lumières“. Wir werden auf diesen Liebesroman in Form des für das 18. Jahrhundert charakteristischen Briefromans später noch zurückkommen.

Nach mehreren Reisen nahm Rousseau auf Anraten seiner späteren Geliebten 1732 in Besançon ein Musikstudium auf, welches er freilich erfolglos wieder abbrach. Dennoch brillierte er 1741 in Paris auf dem Gebiet der Musik, was ihm wichtige Kontakte mit französischen Philosophen und Autoren wie Fontenelle, 
Marivaux oder Diderot eintrug. Die Musik begleitete Rousseau ein Leben lang; als Komponist musikalischer Werke, als Theoretiker von Musik oder als Kopist von Musikstücken, womit er sich in bestimmten Phasen seines Lebens über Wasser halten konnte. Denn in dieser Funktion galt er als überaus präzise.

Weniger präzise ausgerichtet war sein beruflicher Werdegang. Denn in der Folge führten ihn diverse Beschäftigungen etwa als Sekretär und Faktotum nach Venedig, von wo aus er 1744 aber wieder nach Paris zurückkehrte. In der französischen Hauptstadt arbeitete er an verschiedenen Opern und Singspielen - nichts hätte einen in diesem jungen Mann den späteren Philosophen und Schriftsteller vermuten lassen, als welcher er in die Geschichte einging. Er zog mit Thérèse Levasseur zusammen, mit der er insgesamt fünf Kinder zeugte, welche ausnahmslos ins Waisenhaus gegeben wurden. Gleichwohl wurde er zu einem der für das 18. Jahrhundert fortschrittlichsten Theoretiker zeitgenössischer Pädagogik. Rousseau galt damals aber vor allem als ausgesprochener Fachmann auf dem Gebiet der Musik, worüber er später den einschlägigen Artikel in d'Alemberts und Diderots Encyclopédie verfasste. Seine Lettre sur la musique française von 1753 fand große Beachtung beim französischen Publikum.

Der Kopf der berühmten Encyclopédie, Denis Diderot, war es auch, der Rousseau wesentlich zu seinem ersten Discours sowie seinem zweiten Discours sur l'origine et les fondements de l'inégalité parmi les hommes anregte. Vor allem das letztgenannte Werk bildete die Grundlage für Rousseaus Aufstieg zum „Philosophe“ und Vertreter der Aufklärung. Zugleich zeichnete sich schon früh sein Bruch mit den Aufklärungsphilosophen um die Encyclopédie ab, insofern Rousseau ein gänzlich anderes Entwicklungsmodell der (europäischen) Gesellschaft entwarf. Seine Lettre à d'Alembert von 1758 vollzog mit der Abwertung des Theaters als moralischer Anstalt diesen Bruch bewusst, isolierte Rousseau aber zunehmend. Die Trennung von den einstigen philosophischen Mitstreitern lastete schwer auf Rousseaus Schultern und führte ihn dazu, sich immer stärker von der Pariser Bühne der an Frankreich ausgerichteten République des Lettres zurückzuziehen. Das Bild vom ,Einsiedler` Rousseau machte bald die Runde: Für große Teile des damaligen Lesepublikums wurde der „Citoyen de Genève“, der als Philosoph wie als Schriftteller seine eigenen Wege ging, fortan zum Sonderling.

1762 wurde der Verfasser des Contrat social und Staatstheoretiker nach der Veröffentlichung seines Emile von staatlicher Seite in Frankreich verfolgt und entzog sich seiner Festnahme durch Flucht in die Schweiz und später - auf Einladung von David Hume -nach England. Vor allem in seinen Confessions, mit denen wir uns intensiver beschäftigen werden, sowie seinen Rêveries du promeneur solitaire entfaltete er die moderne Form der Autobiographie, in welcher der Selbstreflexion und ständigen Selbstbehauptung wie kritischen Selbstbefragung eine wichtige Rolle zukommt. Mit allen Mitteln der Literatur gestaltete Rous- 
seau die Zerrissenheit des modernen Subjekts akribisch nach und schrieb aus einer Position der Abspaltung von seinem Publikum die sicherlich präzisesten Darstellungen eines Ich, das an seiner Einzigartigkeit freilich nicht zu zweifeln vermag. Auch wenn das Pariser Publikum zunächst seine Bekenntnisse unschlüssig und teilweise perplex aufnahm, waren sie doch von ungeheurer Bedeutung nicht allein für die Gattung der Autobiographie, sondern auch für das auf uns gekommene Bild von Jean-Jacques, wie er selbst in der literaturwissenschaftlichen Forschung immer wieder genannt wird. Denn der Verfasser von Les Confessions trat seinem Lesepublikum textextern erhobenen Hauptes, mit dem Buch seines Lebens in der Hand und dem gut in Szene gesetzten Versprechen entgegen, sich ganz so zu zeigen, wie er war.

Doch nicht nur in Les Confessions erwies sich Rousseau als überragender Schriftsteller, der in Frankreich und ganz Europa, aber auch längst in Übersee große Erfolge für sich verbuchen konnte. Sein Briefroman Julie ou la Nouvelle Héloïse wurde zu einem der großen Bestseller des Jahrhunderts der Aufklärung und wird im Zentrum unserer nachfolgenden literaturwissenschaftlichen Analyse stehen. Zugleich blieb der Citoyen de Genève für einen wichtigen Teil der französischen Aufklärungsphilosophie eine Zielscheibe des Spotts und der gehässigen Satire. Die Tatsache, dass ihn sein früherer Freund Denis Diderot 1778 in seinem Essai sur les règnes de Claude et de Néron als Verbrecher darstellte, der die Maske des Heuchlers trage, blieb bei weitem nicht der einzige Angriff, dem der Philosoph aus Genf in Frankreich ausgesetzt war. Umso mehr drängte es ihn, sich in immer neuen Spiegelungen literarisch seinem Lesepublikum als ganzen Menschen, als Menschen in seiner Ganzheit zu präsentieren. Dieses Begehren war, wie wir noch sehen werden, literarisch höchst produktiv.

Doch die Anhänger Rousseaus, zu denen unter anderem Bernardin de SaintPierre, Louis-Sébastien Mercier oder Germaine de Staël zählten - und ich darf Sie an dieser Stelle erneut auf die Vorlesung über die Romantik zwischen zwei Welten verweisen $^{2}$-, traten vehement für den verstorbenen Genfer Bürger ein und betonten den Zusammenhang zwischen dessen der gesellschaftlichen Entwicklung gegenüber pessimistischem Denken und seiner eigenen Lebensführung. JeanJacques' Erbe wirkte ebenso im Bereich der Philosophie und des politischen Handelns wie im Bereich der „Belles-Lettres“. Im Kontext der Französischen Revolution blühte ebenso ein Rousseau-Kult auf wie die Verehrung von JeanJacques im Kontext einer vor- und frühromantischen Ästhetik, als deren Wegbereiter der Autor von Julie ou la Nouvelle Héloïse bald schon galt.

2 Vgl. Ette, Ottmar: Romantik zwischen zwei Welten, S. 69-99 u. 493-518. 
Jean-Jacques Rousseaus schier unaufhaltsamer Siegeszug als Philosoph, als Schriftsteller und öffentliche Figur begann schon zu Lebzeiten, nahm nach seinem Tod aber einen noch viel stärkeren Verlauf, auch wenn man nicht scharf genug zwischen Rousseau und dem Rousseauismus unterscheiden kann. 1794 wurden seine sterblichen Überreste ins Pariser Panthéon überführt: Die Französische Revolution hatte ihn nach seinem Tod zu einem ihrer wichtigsten Vorläufer gemacht. Gerade die Romantiker unterstrichen den von Rousseau ihrer Meinung nach evidenten Sinnverlust der Gesellschaft im Lichte eines Kulturpessimismus, dem man die Züge Rousseaus gab. Hätte für die Anhänger der romantischen Schule in Europa wie in Übersee das 18. Jahrhundert ein Gesicht gehabt, dieses Gesicht hätte die Züge des „Citoyen de Genève“ getragen. Rousseau stand so als Literat wie als öffentliche Figur für die unterschiedlichsten Entwicklungen Pate - von der Französischen Revolution bis hin zum kulturpessimistischen Zweig der Romantik. Seine Rolle als intellektueller Impulsgeber kann daher kaum überschätzt werden.

Rousseaus Les Confessions stellen die erste Autobiographie im modernen Sinne und zugleich die erste Autobiographie in der Moderne dar. Um besser zu verstehen, inwiefern die Rousseau'sche Autobiographie sich von der literarischen Gattung der Memoiren unterscheidet und abgrenzt, der sich im 18. Jahrhundert vorwiegend Angehörige des hohen Adels bedienten und in unserer Epoche vor allem Politiker und all jene, die sich für ,Very Important Persons“ halten, werden wir uns eines Close Reading, mithin einer sehr genauen, präzisen Textlektüre bedienen. Die nicht selten allographen, also von anderen als der porträtierten Person verfassten Memoiren ziehen ihren Seins-Grund aus der Tatsache, dass sich die oder der Dargestellte mit vielen hochwichtigen Persönlichkeiten traf, welche allesamt zur Freude des an derartigen VIP's interessierten Leserinnen und Lesern dargestellt werden müssen. Im Unterschied dazu zieht das Eigen-Leben-Schreiben der Autobiographie - denn nichts anderes bedeutet dieser Ausdruck etymologisch - seine Bedeutung aus der Außerordentlichkeit des repräsentierten Subjekts, das sich in seiner ganzen Vielschichtigkeit zu erkennen gibt. Und dies bedeutet, dass eine Vielzahl komplexer literarischer Verfahren zur Ausführung kommen und analysiert werden wollen.

Beginnen wir also mit der Analyse dieses sicherlich zentralen Texts des um es noch einmal zu wiederholen - 1712 in Genf geborenen, sich sein Leben lang stolz als „Citoyen de Genève“ apostrophierenden und 1778 in Ermenonville verstorbenen Jean-Jacques Rousseau, der mit der Niederschrift der ersten Fassung seiner Confessions im Jahr 1764 begann. Dieses Vorhaben von Rousseau wurde dabei durchaus unterstützt von einem enormen verlegerischen Interesse an den Bekenntnissen dieses großen Repräsentanten der französischsprachigen 
Aufklärung: Die Verleger erhofften sich ein lukratives Geschäft. Sie sollten nicht enttäuscht werden - zumindest mittelfristig betrachtet.

Aber es sollten eben keine Memoiren werden, sondern ein gänzlich anders gearteter Text, mit dessen literarischen ,Gemacht-Sein' wir uns nun beschäftigen wollen. Beginnen wir dabei mit dem Incipit, mit den ersten Sätzen dieser Confessions:

Ich gestalte eine Unternehmung, welche niemals zuvor je ein Beispiel hatte, und deren Ausführung keinerlei Nachahmer finden wird. Ich will Meinesgleichen einen Menschen in der vollständigen Wahrheit der Natur zeigen, und dieser Mensch werde ich sein.

Ich allein. Ich fühle mein Herz und ich kenne die Menschen. Ich bin gemacht wie kein einziger derer, die ich gesehen; ich wage zu glauben, dass ich wie keiner gemacht bin von all jenen, die existieren. Bin ich nicht mehr wert als diese, so bin ich doch zumindest anders. Wenn die Natur es gut oder schlecht tat, die Form zu zerbrechen, in die ich gegossen ward, so ist dies etwas, das man nur beurteilen kann, nachdem man mich gelesen.

Möge die Trompete des Jüngsten Gerichts ertönen, wann auch immer sie will: Ich werde mit diesem Buch in der Hand kommen, um mich vor dem Höchsten Richter zu präsentieren. Ich werde es laut sagen: Hier ist, was ich gemacht, hier ist, was ich gedacht, hier ist, was ich war. Ich habe das Gute und das Schlechte mit derselben Offenheit gesagt. Ich habe nichts Schlechtes verschwiegen, nichts Gutes hinzugefügt, und wenn es mir widerfuhr, irgend eine gleichgültige Ausschmückung zu benutzen, so geschah dies nie, um eine Leere zu tilgen, die einem Fehler meines Gedächtnisses entsprang; ich konnte als wahr annehmen, was ich als solches wissen konnte, und niemals das, was ich als falsch erkannt. Ich habe mich gezeigt, so wie ich war, verachtenswert und gemein, wenn ich es war, gut, großzügig und erhaben, wenn ich dies war: Ich habe mein Innerstes entschleiert, so wie $\mathrm{Du}$ es selbst gesehen. Oh Ewiges Wesen, versammle um mich her die unzählige Masse aller, die mir gleichen; mögen sie meine Bekenntnisse hören, mögen sie über mein unwürdiges Verhalten seufzen, mögen sie über all meine Erbärmlichkeit erröten. Möge ein jeder von ihnen am Fuße Deines Thrones sein Herz mit derselben Aufrichtigkeit enthüllen; und möge Dir dann auch nur ein einziger sagen, wenn er es wagen sollte: Ich war besser als dieser Mann. ${ }^{3}$

Dies also sind die berühmt gewordenen Anfangsworte der wohl ersten und damit gattungsbegründenden Autobiographie der Welt: Jean-Jacques Rousseaus Les Confessions! Wenn sich Rousseau gleich im ersten Satz seiner Autobiographie in einem täuschte, dann darin, dass seine „entreprise“ keine Nachahmer finden würde: Denn die Nachahmer der von ihn geschaffenen autobiographischen Form sind Legion - und noch heute werden es tagtäglich mehr. Fast ebenso zahlreich sind die literarischen Formen autobiographischen Schreibens, die sich von diesem literarischen ,Big Bang‘ herleiten.

3 Rousseau, Jean-Jacques: Les Confessions. Paris: Launette 1889, I, S. 1 f. 
Doch nichts kommt in der Literatur, in den Literaturen der Welt aus dem Nichts! Dies bewahrheitet sich auch bei diesem Unterfangen des illustren Genfers. Denn Rousseaus Les Confessions spielen bereits in ihrem Titel auf die Confessiones des Augustinus an, betonen zugleich aber massiv und wiederholt, eine zuvor nie dagewesene Form und Reflexion eines Menschen darzustellen, die es so nie wieder geben werde. Auch wenn wir heute wissen, dass auch dieser Text keine creatio ex nihilo ist und auf eine Vielzahl von Vorläufern zurückblicken kann, so handelt es sich doch um ein Buch, das gattungsgeschichtlich wie literarhistorisch einen Einschnitt markiert, gerade weil es repräsentativ für eine generelle und keineswegs nur individuelle Entwicklung steht. Denn Les Confessions von Jean-Jacques Rousseau sollten den Weg bereiten für eine der großen literarischen Gattungen, die im Zeichen des Autobiographischen die Literaturen der Moderne prägten - sowie für die Entfaltung jener Epoche und jenes Denkens, das wir gemeinhin mit dem Begriff der Romantik belegen.

Ich möchte Ihnen ausgehend vom Incipit die große Unternehmung des Jean-Jacques als den Versuch beschreiben, die Erfindung des modernen Subjekts in diesem wie auch eventuell in nachfolgenden Werken anzugehen und zu bewerkstelligen. Rousseau ist ganz gewiss nicht der Erfinder der modernen Subjektivität, zu deren Genese ein Joachim Ritter bereits wertvolle Hinweise gab, ${ }^{4}$ wohl aber die gewiss gewichtigste Stimme derer, die dieses Subjekt für die Moderne neu erfanden. So wird es im Folgenden vorrangig um eine Beleuchtung jener Aspekte und Entwicklungen gehen, die für die unterschiedlichsten Aspekte der Herausbildung moderner Subjektivität im Akt des Lesens wie im Akt des Schreibens stehen. Denn in Les Confessions wurden die Grundlagen für ein Schreiben und Lesen gelegt, welche im Kontext eines Lebens in der Moderne von entscheidender Bedeutung waren.

In Les Confessions geht es also erstmals um die bewusste Entfaltung moderner Subjektivität und damit um eine Konstellation, die selbst aufgrund ihrer Infragestellung erneut seit der zweiten Hälfte des 20. Jahrhunderts im Zeichen der vorwiegend französischen (Neo-)Avantgarden $\mathrm{zu}$ einem fortdauernden Referenzpunkt philosophischen und literarischen Schreibens geworden ist. Noch Alain Robbe-Grillets Tintenspiegel sind ohne die Schreib- und Leseerfahrungen eines Jean-Jacques nicht zu denken. Gehen wir jedoch bei unserer Annäherung - dem Verfahren eines Close Reading nahe - Satz für Satz vor und haben wir dabei stets auch das französische Original vor Augen: Denn die Worte und die Wendungen, welche Rousseau gleich zu Beginn dieses Buchs wählt, haben es in sich!

4 Vgl. hierzu Ritter, Joachim: Subjektivität. Sechs Aufsätze. Frankfurt am Main: Suhrkamp 1989. 
Das Incipit und der Anfangssatz beginnen mit einem Ich, einem „Je“, ganz so, wie auch der zweite Satz - und eine Reihe weiterer Sätze - mit der ersten Person Singular anhebt und der erste Abschnitt auch mit einem „moi“ endet, also erneut mit einem betonten Verweis auf die erste Person. Im Zentrum aller Überlegungen, aller Fokussierungen, steht von Beginn an das Subjekt.

Zugleich ist dieser erste Satz autoreflexiv, bezieht sich also auf das Buch selbst und besitzt damit einen metadiskursiven Status, der gleich im ersten Absatz souverän ausgeführt und ausgespielt wird. Auf Inhaltsebene propagiert er seine eigene Einmaligkeit: Weder Beispiele oder Vorläufer gebe es noch Nachfolger oder Nachahmer werde es je geben können. Das ist von Beginn an starker Tobak: Rousseaus Text behauptet, um es im aktuellen Bürokratendeutsch zu sagen, sein unbedingtes Alleinstellungsmerkmal. Der Einzigartigkeit der vom Verfasser ins Auge gefassten Unternehmung entspricht aber zugleich die Einzigartigkeit des von ihm dargestellten und in Szene gesetzten Subjekts.

Damit kommt eine wesentliche Dimension von Beginn an in den Text: das Moment der Einmaligkeit, des Unwiederholbaren und der gesamte Pathos, der diesem großen Augenblick, diesem herausragenden Moment der Fertigstellung dieses Buches eignet, mit dem der Verfasser vor seinen Schöpfer, vor Gott selbst tritt. Dabei ist das Sujet nicht mehr ein Mensch als Unterworfener, der seinem absoluten, göttlich legitimierten Herrscher entsprechend unterwürfig gegenübertritt, sondern ein modernes Subjekt, das seinem Schöpfer kühn ins Auge blickt und mit diesem gleichsam auf Augenhöhe ist.

Das Ich dieses ersten Satzes stellt überdies nun eine direkte Brücke her zwischen der textinternen Instanz des Ich-Erzählers und der textexternen Instanz des realen Autors, des Schriftstellers mit Namen Jean-Jacques Rousseau. Es ist ein Ich, in welchem sich diese Linien kreuzen. Es führt damit jene gattungskonstitutive Dimension ein, die Philippe Lejeune ${ }^{5}$ als den autobiographischen Pakt bezeichnete, also die Übereinkunft, welche - grob gesagt - der reale Leser mit dem realen Autor über den literarischen Text und dessen Figuren (und Figurationen des Ich) trifft. Es geht um die Identität zwischen der textinternen Instanz (wir werden gleich sehen, dass es deren mehrere gibt) und der textexternen Instanz und damit um die Frage, ob wir also die Textfigur des Ich mit dem textexternen realen Schriftsteller identifizieren wollen oder nicht. Spricht das Ich für den Autornamen, für den es stellvertretend auftritt? Im Incipit der Confessions wird von Anfang an also das schriftstellerische Projekt, die „entreprise“, als eine Art Schwelle zwischen textexterner und textinterner Ebene benutzt und damit in der ersten Person Singular gebündelt. Dies hat weitreichende Konse-

5 Vgl. die klassische Studie von Lejeune, Philippe: Le pacte autobiographique. Paris: Seuil 1975. 
quenzen nicht nur für die verschiedenen ,Benennungen“, sondern für das moderne Subjekt selbst.

Doch verweilen wir noch einen Augenblick beim ersten Satz, zweifellos einem der berühmtesten Auftaktsätze innerhalb der Literaturen der Welt. Denn die Tatsache, dass es für die Confessions - und gerade die Wahl des an Augustinus angelehnten Titels spricht dagegen - kein Beispiel, kein Vorbild gebe, macht uns darauf aufmerksam, dass wir es hier mit einem Ausscheren aus literarischen Traditionen, aber vielleicht auch aus gesellschaftlichen Konventionen und Normen zu tun haben. Dieses konstituiert nun den Raum des Eigenen, den Raum des Ichs, den Raum der Subjektivität, der mit der Originalität und Einmaligkeit der gesamten Unternehmung verbunden ist. Die Einmaligkeit und Unwiederholbarkeit des Subjekts meint nicht dessen Ursprungslosigkeit: Es gibt Ursprünge, doch unterliegen sie einer radikalen Transformation, was vom Titel an unmittelbar und direkt signalisiert wird.

Das sich ins Zentrum rückende Subjekt etabliert sich damit schon über sein Schreib- und Lese-Projekt in einem Zwischenraum zwischen der Masse der Gesellschaft und allerhöchster Individualität. Es ist ein Subjekt, das unverwechselbar ist. Denn es ist auch innerhalb eines geschichtlichen Ablaufs ohne Vorläufer und ohne Nachfolger: Es ist einzig und einzigartig: Seine Vorläufer sind einzig dazu da, diesem nie dagewesenen Subjekt den Weg freizumachen und sich als Zeugen vor dem Einzigartigen zu verneigen. Auch dies ist von grundlegender Bedeutung für die Konstituierung moderner Subjektivität, jener Konstellation, von welcher der französische Philosoph und Wissenschaftshistoriker Michel Foucault in Metaphern des Transitorischen sprach. Erinnert sei an den berühmten - berüchtigten - letzten Abschnitt seines Buches Les mots et les choses aus dem Jahr 1966:

Wenn diese Dispositionen verschwänden, so wie sie entstanden sind, wenn durch irgendein Ereignis, dessen Möglichkeit wir höchstens vorausahnen können, aber dessen Form oder Verheißung wir im Augenblick noch nicht kennen, diese Dispositionen ins Wanken gerieten, wie an der Grenze des achtzehnten Jahrhunderts die Grundlage des klassischen Denkens es tat, dann kann man sehr wohl wetten, dass der Mensch verschwindet wie am Meeresufer ein Gesicht im Sand. ${ }^{6}$

Wir können in diesen Auftaktpassagen das vollständige Erscheinen dieses Menschen in der Form des modernen Subjekts mit all seinen ,Ausstattungen', das heißt all seiner Individualität, Außerordentlichkeit und Einzigartigkeit, erkennen und aus unserer heutigen Perspektive sehen, wie das Gesicht im Sand unter der Wirkung ferner Meere allmählich seine bislang charakteristischen

6 Foucault, Michel: Die Ordnung der Dinge. Frankfurt a. M.: Suhrkamp 1974, S. 462. 
Züge im Wellenschlag verliert. Doch kehren wir rasch vom 21. Jahrhundert zurück in die Mitte des Aufklärungsjahrhunderts, des Siècle des Lumières!

Der zweite Satz nun formuliert den Willen dieses Ich, all seinen „semblables“, also den ihm Gleichen, aber von ihm doch Unterschiedenen, einen Menschen und zugleich einen Mann, wie wir auch mit genderspezifischem Bedeutungsklang sagen könnten, zu zeigen, verbunden mit dem Anspruch auf Wahrheit und von der Natur verbürgt. Dieses Zeigen ist ein Zeigen-Wollen, ein Willensakt, der vom Ich ausgeht: „Je veux montrer.“ Dabei richtet sich dieser Wille auf eine Totalität, also darauf, alles zu zeigen. Das „toute“, die ganze Wahrheit, steht dabei für die Totalität dieses Anspruchs ein: Es ist ein totaler, ja vielleicht sogar totalitärer Anspruch, welcher hier erhoben wird und sich mit dem Ich des Schreibenden verbindet.

Zugleich ist das entscheidende Verb das „montrer“, das Zeigen, das im weiteren Verlauf dieser Passage auch in das „dévoiler“, das Entschleiern, und das „découvrir“, das Aufdecken und Entdecken, übergeht. Wir haben es folglich mit einem Zeigen und Beweisen („démontrer“) der Wahrheit in ihrem absoluten Sinne zu tun, was zugleich auch auf eine Tiefe aufmerksam macht, die nicht der Oberfläche des Menschen und alles Menschlichen, seinen Normen und Konventionen entspricht. Das „montrer“ ist mit dem Willensakt des Ich verbunden und verdeutlicht das Wollen des Subjekts, zu zeigen, zu belegen und $\mathrm{zu}$ beweisen, dass es anders ist als all seine „semblables“, dass es in seinem Sein einzigartig ist und sich auch in seinem Tun, hier in seinem Zeigen, als unvergleichliches Individuum erweist.

Doch genügt es nicht, allein $\mathrm{zu}$ schreiben und $\mathrm{zu}$ zeigen. Es muss eine Kommunikationssituation hergestellt werden, um überhaupt erst alles in Bewegung zu setzen. So braucht es Leserinnen und Leser. Das Zielpublikum aller Lektüren ist klar formuliert, klar ausgemacht: Die Konstituierung des Ich benötigt die Präsenz eines Lesepublikums. Denn moderne Subjektivität kann sich in einem modernen Sinne nur dann konstituieren, wenn sie sich anderen zeigt, mit anderen kommuniziert, sich von anderen abgrenzt und als different darstellt. Mit anderen Worten: Subjektivität konstituiert sich erst, wenn ihr Schreiben oder Handeln ostentativ wird und von einer Latenz in etwas Manifestes übergeht. Der Mensch, der gezeigt werden soll, ist das „moi“, ist das Ich. Damit kommt nun der autoreflexive Charakter in die autobiographische Strukturierung hinein. Denn das moderne Subjekt vermag sich nur dadurch zu konstituieren, dass es sich selbst reflektiert.

Diese Autoreflexivität hat Folgen, insoweit diese zu einer Duplizierung, zu einer Verdoppelung führt. Das Zurückbeugen des Ich auf sich selbst führt zu einem zweiten Ich, das hier im betonten Personalpronomen in anderer Form erscheint, in einer Form, die wir im deutschen nicht nachahmen können - als ein 
„moi“, das noch immer derselbe Mensch zu sein scheint, und doch vom ,je“ her gezeigt und konstruiert wird. Die Betonung dieses Ich, dieses „moi“, wird noch dadurch erhöht, indem ihm ein zweiter Einsilber an die Seite gestellt wird, der gleichsam explodiert: „Moi seul.“ Das Ich, das hier als „Ich allein“ auftritt, hat sich verdoppelt: Es tritt auseinander in ein zeigendes Ich und in ein gezeigtes Ich, die im Französischen von ,je“ und „moi“ stellvertretend re-präsentiert werden.

Machen wir uns diese Verdoppelung klar: Das eine Ich ist das Subjekt des Vorgangs des Zeigens und das andere Ich ist das Objekt desselben Vorganges und wird somit gezeigt! Es kommt damit zu einer Spaltung, zu einer Trennung; ganz so, wie das Projekt des Schreibens selbst eine Trennung, eine Spaltung gegenüber allen anderen Projekten ankündigte und hier nun eine andere Dimension der Konstituierung von Subjektivität einbringt. Moderne Subjektivität beruht auf dieser Spaltung. Damit deutet sich eine Spaltung an in ein erzählendes oder wenn sie so wollen zeigendes Ich und ein erzähltes, dargestelltes oder gezeigtes Ich, das freilich in seiner ganzen Wahrheit schonungslos entschleiert werden soll. Dies ist ein wichtiger gattungskonstitutiver Augenblick, der sehr früh in Rousseaus Confessions erscheint. Man könnte daran freilich die Frage anknüpfen, ob denn zusätzlich zum gezeigten Ich, das vollständig gezeigt werden soll, auch das zeigende Ich einer solchen totalen Entschleierung unterliegt.

Doch stellen wir die Frage nochmal anders und verändern wir die Perspektivik! Die soeben gewählte Benennung zeigendes versus gezeigtes Ich nehme ich an dieser Stelle nur aufgrund der entsprechenden Textvorgabe; denn im Grunde handelt es sich bei beiden Ichs um gezeigte und auch konstruierte IchFiguren. Ich möchte sie also nur vorläufig heranziehen. Denn an einem kann es keinerlei Zweifel geben: Bei beiden geht es nicht um den realen Autor, also um Jean-Jacques Rousseau, sondern um Subjektkonstruktionen im innerliterarischen Raum. Dies bedeutet, dass die Vervielfachung des Ich weitaus größer ist als eine simple Duplizierung, dass die Spaltung des Ich mit einer Vervielfachung von Ich-Figuren einhergeht. Die Fiktion - auch gerade die Fiktion der Wahrheit und der absoluten Aufrichtigkeit - gestaltet und bildet den Raum, innerhalb dessen sich die Authentizität des Ich konstruieren lässt und gleichsam erprobt, experimentell untersucht und konstituiert werden kann. Diese Fiktion des Ich ist durch die Aufspaltung oder Vervielfachung in verschiedene Ichs von Beginn an eine Friktion ${ }^{7}$ : Sie pendelt mithin zwischen textexterner Wirklichkeit und innerliterarischer Imagination.

7 Vgl. zum Begriff der Friktion Ette, Ottmar: Roland Barthes. Eine intellektuelle Biographie. Dritte, unveränderte Auflage. Berlin: Edition Suhrkamp 2012, S. 308-312. 
Vor diesem Hintergrund ergibt sich die Anlage des gesamten Buchs überdies als ein ständiges Pendeln zwischen den beiden Ichs, dem ,je“ und dem „moi“, die sich selbstverständlich auf zwei verschiedenen Zeitebenen ansiedeln, welche sich zumindest tendenziell im weiteren Verlauf von Les Confessions einander annähern werden. Geht es beispielsweise um die Geburt des erzählten Ich, dann ist der zeitliche Abstand zum erzählenden Ich sehr groß; geht es um das Alter des erzählten Ich, dann ist der zeitliche Abstand zum erzählenden Ich relativ gering. Nicht umsonst beginnt nach diesem Incipit der Text mit dem Beginn, mit der eigenen Geburt und damit mit einem Datum, das schlechterdings nicht aus der Perspektive eigenen Erlebens gezeigt und dargestellt werden kann. Denn wir sind bei unserer Geburt zwar selbstverständlich anwesend, können sie aber nicht aus dem eigenen Erleben bewusst reflektieren und aus der Distanz schildern. ${ }^{8}$ Die Literatur kann durchaus diesen Augenblick der Geburt gestalten; und sie hat dank der langen Geschichte der Literaturen der Welt sehr viele literarische (und literarisch akkumulierte) Mittel dafür. Doch befinden sich diese außerhalb der klassischen Autobiographie und zugleich in einem thematischen Bereich, dem eine eigene Vorlesung gilt. Dieser Vorlesung, die Sie im nächsten Semester erwartet, will ich freilich nicht vorgreifen ...

Der zweite Absatz des Incipit führt die beobachtete Konzentration auf das Ich radikal weiter. War es zunächst um einen Menschen, einen Mann überhaupt gegangen, der in seiner ganzen Wahrheit gezeigt werden sollte, so geht es nun um das Ich, das an die Stelle von „un homme“ tritt. Als Objekt des Schreibens wird allein das Subjekt herausgestellt. Jetzt also tritt das Ich auf, es erscheint definitiv auf der Bühne des Textes, gibt sich dem Lesepublikum in seiner ganzen Größe preis: Es erscheint das Ich, das „moi“ allein: „Moi seul.“ An die Seite des Totalitätsanspruchs tritt hier nun der Individualitätsanspruch und zugleich, das Wörtchen ist fürwahr verräterisch, das „seul“, das Alleinige, das Einzige, aber auch das Einsame, das Individuum, das von allen anderen abgetrennt wird und sich in seiner Eigenheit und Einsamkeit zugleich präsentiert. Noch im Titel der Rêveries d'un promeneur solitaire taucht dieses einzigartige und einsame Ich wieder auf. Doch dazu später mehr, umfasste die „entreprise“ des Zeigens doch nicht allein die Niederschrift von Rousseaus Les Confessions, sondern auch anderer autobiographischer Vorhaben des Genfer Schriftstellers.

Gezeigt wird allein das Ich: allein das gezeigte Ich. Aber vielleicht deutet sich hier auch schon an: Es folgt und erfolgt der Leseauftritt des Ich allein, als Ich allein, das Ich in seiner Einsamkeit, als sich gegenüber der Gesellschaft, gegenüber den „semblables“ als von diesen getrenntes Ich auffasst und kraft sei-

8 Vgl. hierzu die Potsdamer Vorlesung von Ette, Ottmar: Geburt, Leben, Sterben, Tod (2022). 
nes Willens konstruiert. Die (rhetorische, literarische und philosophische) Ellipse des „moi seul“ ist daher von einem ungeheuren Gewicht. Sie wird in keinen Satz eingebunden und steht für sich allein. Und Rousseau hat mit dieser Formel tatsächlich noch einmal beide Gedanken zusammengefasst: Das Vorhaben wie der Gegenstand des Vorhabens werden von diesem Ich allein bestritten. Damit ist die Einsamkeit, aber auch die Originalität erfasst: die Originalität des Vorhabens wie des Ich selbst, das nicht nur als gezeigtes, sondern auch als zeigendes Ich einzigartig und unvergleichlich ist. Das Ich wird selbst - ganz etymologisch - zum Urheber seiner selbst und des Vorhabens oder der Unternehmung, wird zum Chef der „entreprise“, ganz das Ich allein.

Daraus ergibt sich eine grundsätzliche Problematik: jene der Beziehung ja der trennenden Beziehung - zwischen diesem einmaligen, diesem unhintergehbaren Ich und der Masse der Menschen, seinen „semblables“, die ihm nur ähnlich sind und denen er gegenübertritt. Diese Problematik ist dem Ich von Beginn an bewusst: Sie ist Teil der Problematik moderner Subjektivität. Und eben hier setzt die Beziehung zwischen moderner Subjektivität und Kollektivität an: „Ich fühle mein Herz und ich kenne die Menschen, Je sens mon cour et je connais les hommes."

Was in und mit diesen simplen Worten geschieht, ist eine Art Verortung des Anderen, der Menschen an und im eigenen Körper des Ich. Das Herz wird zum Organ der Erkenntnis der anderen, wird zum Erkenntnisorgan der Menschen überhaupt, insoweit es vom Fühlen (dem „sentir“) direkt den Zugang zum Wissen (dem „connaître“) herzustellen vermag. Zugleich übersteigt das gefühlte Herz in seiner ich-bezogenen Erkenntnis die Schwelle zwischen Individuum und Kollektivität auf eine überraschende, ja geradezu schockierende Weise: Wieso sollte das zentrale Organ eines Ich, das doch von allen anderen unterschieden ist, gerade diese anderen kennen und erkennen?

Affektives Gefühl und intellektuelle Erkenntnis vereinigen sich an diesem Punkt. Das Individuum wird damit zu einer Art Synekdoche, zu einem pars pro toto der gesamten Menschheit - oder sollten wir geschlechterspezifisch besser sagen ,Mannheit‘? Dadurch ergibt sich eine generelle Verschränkung zweier Bewegungen, die wir durchaus als Paradox verstehen dürfen: Das Ich ist anders, einzigartig wie sein Vorhaben, von allen Menschen geschieden, allein - und doch zugleich mit allen anderen verbunden über das Organ seines eigenen Herzens. Über das Herz verläuft die Verbindung zur Kollektivität, über das gefühlte Herz - und nicht etwa über das Gehirn, den Intellekt - ergibt sich die Verbindung des modernen Subjekts mit der gesamten Menschengattung.

In diesem Zusammenhang entwickelt sich eine Topographie des Körpers, eine Anordnung von Körperorten, die von größter Bedeutung für die Topographie, die Schreib- und Leseweise, aber auch die Körperlichkeit von Empfindsam- 
keit und Romantik werden wird. Es ist eine Schreibweise, die an das Herz als Schreiborgan angeschlossen ist und in gewisser Weise eine erkaltete Herzensschrift darstellt. Angedeutet wird in diesen Formulierungen, was ich in unserer Vorlesung über die Romantik zwischen zwei Welten bis hin zu Juana Borrero ausgeführt habe, jener kubanischen Dichterin, die an ihren Geliebten einen berühmten Brief mit der Tinte ihres eigenen Blutes schrieb. ${ }^{9}$

Wir finden all dies höchst entwickelt im Diskurs der Romantik und vor allem im romantischen Liebesdiskurs, der sich als Diskurs der Erkenntnis des Herzens präsentiert. Denn dort ist das Herz ebenfalls das zentrale Organ: Es wird vom Blut durchströmt, das letztlich jene Flüssigkeit darstellt, welche metaphorisch neben die Flüssigkeit der Tinte beim Schreiben tritt. Das moderne Subjekt ist nicht nur vom Intellekt gesteuert: Es ist Teil eines strömenden, allpräsenten und mit Intellekt und Erkenntnis verquickten Körper-Leibes, in welchem sich der Körper als ein Körper-Haben und der Leib als ein Leib-Sein miteinander unauflöslich verschränken.

Selbst das intime Transportmittel, das vom Herzen circa sechzigmal pro Minute angesaugt und abgepumpt und damit in ständiger Bewegung gehalten wird, kann von der Ebene des Leib-Seins in die Objektivierung eines KörperHabens überführt und damit in ein Objekt verwandelt werden, welches das Ich benutzen kann. Es ist das Blut als rote Tinte, die erkaltete Spur des Herzens, zur Herzensschrift koaguliert, welche tiefste Erkenntnis sein will. Die Erkenntnisse dieses Herzens, soviel dürfen wir festhalten, bleiben nicht auf den eigenen Körper, auf die Erkenntnis des eigenen Ich beschränkt, sondern werden entgrenzt, übersteigen das Eigene, den eigenen Körper-Leib. Sie geben Auskunft über die gesamte Menschheit, unabhängig von ihrer Kultur, ihrer Zivilisation oder Religion: Je sens mon cœur et je connais les hommes. Der Anspruch des Rousseau'schen Ich ist selbstverständlich universal. Keine kulturelle Differenz, keine genderspezifischen Erfahrungen, nichts entzieht sich einer Erkenntnis, die aus den Tiefen des von Rousseau in Szene gesetzten Körpers kommt.

Ist diese die gesamte Menschheit umfassende, umspannende und im vollen Wortsinne universalistische Verbindung erst einmal hergestellt, bedarf es zugleich auch einer Betonung der Abtrennung des Nicht-Trennbaren, des In-Dividuums: Ich bin gemacht wie keiner all jener, die ich je gesehen. Das moderne Subjekt konstruiert sich als ein Anderes, als „autre“, um sich im selben Atemzug zum Eigenen zu machen, das sich von allen Anderen abspaltet und ihnen gegenübertritt. Noch scheint das Fremde in diesem Eigenen nicht auf, auch wenn dieses Fremde in der Aufspaltung in eine Vielheit der Ichs implizit schon präsent ist. Denn das moderne

9 Vgl. Ette, Ottmar: Romantik zwischen zwei Welten, S. $1049 \mathrm{ff}$. 
Subjekt hat aufgehört, ein homogener Block, ein Monolith zu sein, den nichts zu spalten vermag. Spaltungen sind, wie wir bereits sahen, konstitutiv für die moderne Subjektivität.

An dieser Stelle wird zugleich die Parallele zwischen Ich und Schreibprojekt im Vorhaben Jean-Jacques Rousseaus offenkundig. Das Ich ist ebenso konstituiert und konstruiert wie das Projekt der Confessions selbst: nämlich aus dem Bewusstsein einer radikalen Differenz heraus. Wir könnten hinzufügen: Aus einer Differenz, die gleichsam im eigenen Ich anthropologisch verkörpert wird, in ihm verkörpert ist. Die radikale Differenz verkörpert sich als Alterität. Erst ein Arthur Rimbaud ${ }^{10}$ wird bei seinem Abschied von der Romantik diese Alterität in das Ich nicht weniger radikal zurückbiegen und zur berühmten Formulierung in seinen Seherbriefen kommen: ,je est un autre“ - Ich ist ein Anderes, ich ist ein Anderer!

Doch davon sind wir bei Jean-Jacques Rousseau in Les Confessions noch weit entfernt, auch wenn selbst diese Spaltung bereits in seinem Denken, in seiner Setzung, in seiner „entreprise“ angelegt ist. Die Betonung des Andersseins verschließt freilich nicht den Zugang zu den anderen, wohl aber die Identifikation mit den „semblables“, mit denen das Ich sich nicht vermischen will. Dies bedeutet wiederum nicht, dass sich nicht die Anderen, dass sich nicht die Leserinnen und Leser mit diesem Ich identifizieren könnten. Denn gerade weil es anders ist und alle Markierungen der Ähnlichkeit trägt, kann es als eine Projektionsfläche für eine sich konstituierende moderne Subjektivität aller Anderen dienen.

Wir werden sehen, dass es über das Herz möglich wird, den Kommunikationsprozess umzukehren und das Herz des Ich zu jenem Organ zu machen, das mir als Leserin oder Leser die Selbsterkenntnis ermöglicht, wobei der Akt des Lesens bei diesem Prozess sehr hilfreich wirken kann, ja bisweilen unabdingbar wird. Immerhin sind von hier, vom Herzen aus alle anderen begreifbar, erkennbar, gleichsam lesbar. Und zugleich erlaubt mir das Herz als kommunikatives, vernetztes Organ die Möglichkeit der Identifikation, die allen Leserinnen und Lesern weit offen steht.

So erkennen wir im Herzen das menschliche Organ, das eine neue Kommunikationssituation zwischen Autor und Leserschaft erlaubt. Denn es sind nicht allein die Gehirne, die sich untereinander austauschen, sondern auch die Gefühle, welche sich miteinander verbinden: Es ist das „sentir“, welches zum „connaître“, zur ganzen Erkenntnis führt. Noch im 18. Jahrhundert wird diese von Rousseau vorgenommene ,Umwertung aller Werte‘, die paradoxerweise zu-

10 Vgl. ebda., S. 901-922. 
gleich eine Beibehaltung aller Werte ist, literarisch wirksam und wird beispielsweise bei seinem Schüler Bernardin de Saint-Pierre und dessen Roman Paul et Virginie erstmals ihre Leistungskraft auch im außereuropäischen Raum erproben. Die Tiefen des Körpers und der Organe sind hier bereits mit der abgründigen Melancholie, in welche der zweite Teil des Romans gekleidet ist, grundlegend beteiligt. Da wir uns ausführlich mit diesem im Indischen Ozean spielenden Roman in unserer Vorlesung über die Romantik zwischen zwei Welten ${ }^{11}$ beschäftigt haben, soll in unserer aktuellen Vorlesung dieses 1789 erstmals veröffentlichte und damit dem 18. Jahrhundert zugehörige Werk nicht ein weiteres Mal besprochen werden.

Im zweiten Abschnitt von Les Confessions betont das Ich das Wagnis einer solchen Abtrennung des Ich, das Wagnis der Behauptung (und des Glaubens, „j'ose croire“) einer radikalen Andersartigkeit des Ich: „Bin ich nicht mehr wert als diese, so bin ich doch zumindest anders." Identität aus der Alterität, so will es zumindest scheinen. Dies ist der Grundsatz der Spaltung zwischen dem Ich und der Gesellschaft, zwischen dem Ich und den Anderen: die Proklamation eines Individuationsprozesses, der freilich nicht transkulturell oder Kulturen überspannend so verläuft, sondern eine spezifische Form westlicher Identitätsbildung darstellt. Denn selbstverständlich ist das moderne Subjekt keine transkulturelle Erfindung, sondern die spezifische Reaktionsweise einer bestimmten kulturellen und gesellschaftlichen Formation auf veränderte Bedingungen in der Zeit der (europäischen) Aufklärung. Werden wir jenseits des Atlantiks ähnliche oder vergleichbare Entwicklungen hin zu einer modernen Subjektivität beobachten können?

Zweifellos haben wir es hier mit der konstitutiven Abtrennung des Ich zu tun, die nicht einmal für die westliche Kultur überhaupt, wohl aber für eine bestimmte Phase der westlichen beziehungsweise abendländischen Kultur grundlegend geworden ist. Es ist die Sattelzeit der Moderne, die jene Züge des menschlichen Antlitzes und des menschlichen Körper-Leibs zeichnete, welche Foucault zwei Jahrhunderte später fast schon im Begriff sah, wie ein Gesicht im Sand von den Wellen des Meeres ausgelöscht zu werden. Das Ich ist unverwechselbar und einzigartig, weil es anders ist; und von dieser Einmaligkeit und Andersartigkeit aus konstruiert es seine Beziehungen zu den Anderen, zur Gesellschaft, zur Kollektivität. In den Begriff der modernen abendländischen Subjektivität ist der Begriff der Alterität - fruchtbar und kreativ, aber auch furchtbar zugleich ${ }^{12}$ - eingeschrieben.

11 Vgl. ebda., S. $69 \mathrm{ff}$.

12 Zur Problematik der Rede vom Anderen und der Alterität vgl. Ette, Ottmar: Weiter denken. Viellogisches denken / viellogisches Denken und die Wege zu einer Epistemologie der Erweiterung. In: Romanistische Zeitschrift für Literaturgeschichte / Cahiers d'Histoire des Littératures Romanes (Heidelberg) XL, 1-4 (2016), S. 331-355. 
Dann folgt eine Metapher, die nicht beiläufig, sondern tief in der abendländischen Kulturgeschichte verwurzelt ist. Denn die Natur hat gleichsam eine Leerform geschaffen, die das Ich gestaltet hat, eine Backform, die das Ich geformt und gebildet hat. Doch die Natur hat diese Form sogleich wieder zerbrochen und für immer dieses Modell, diese Figura zerstört. In der „nature“ wird die Urheberin jener Form des Ich und zugleich auch jene Dimension der ,vérité de la nature“ erkannt, die wir bereits im zweiten Satz bemerkt hatten. Die Natur wird damit auch zum Gegenstandsbereich einer Zugangsmöglichkeit zum Grundlegenden, zur Grundform, auch wenn eine derartige „moule“, eine derartige Leerform wie jene, die für Rousseau gefertigt wurde, niemals mehr auftauchen wird. Das Ich verweigert sich damit jeglichem Versuch, es in eine figurale Geschichte des Menschen zu integrieren, es einer transhistorischen Figura einzuverleiben, welche in immer neuen Wendungen in der Geschichte auftaucht und in nur scheinbar neuer Form zyklisch wiederkehrend erscheint. Mit anderen Worten: Das Ich entzieht sich jeglicher Figuraldeutung, ebenso in der Vergangenheit wie - denn die Form ist zerbrochen - in aller Zukunft.

Zugleich ist das Ich dieser einzigartigen Form entsprungen. Hätte es von der Natur diese Form nicht gegeben, wie hätte es überhaupt entstehen und in die Welt kommen können? Das Ich erscheint in diesen Wendungen als eine von der Natur gegebene Leerform, die es dann erst in einem Prozess sukzessiver Füllung konstituieren wird. Das Ich ist nicht von vorneherein und ein für alle Mal gegeben. Diese von Rousseau gewählte Metapher ist aufschlussreich, denn das vorab Gegebene ist allein die Leerform, auch wenn sie die sich später weiter entwickelnde Vollform modelliert. Noch entscheidender aber ist das Ende dieses Satzes: Denn urteilen und beurteilen könne der Leser erst, wenn er dieses Buch des Lebens gelesen habe. Entscheidend mithin ist die Lektüre: entscheidend der Andere, der den Text liest.

Doch sehen wir genauer hin: Denn der Leser liest im eigentlichen Sinne nicht das Buch, sondern das Ich - nachdem er mich gelesen hat! An die Stelle des Buchs und des Buchprojekts tritt hier also endlich das ,ich“, das unbetonte Personalpronomen, das interpretiert, entziffert, gedeutet, eben gelesen werden kann. Im Mittelpunkt also stehen die Lektüre und das Lesen des Ich, des modernen Subjekts, das einen Leser braucht.

Damit tritt explizit jene Identifikation von Ich und Buch ein, die in der Parallelisierung bereits angelegt war, nun aber erst zum Tragen kommt: Das Ich ist das Buch, das in einem längeren Leseprozess einer aufmerksamen Lektüre unterzogen und erst danach be- oder verurteilt werden kann. Die Leserschaft ist essentiell für das moderne Subjekt, das weit davon entfernt ist, autonom zu sein. Dieser Leser, der das Ich studiert, kann ein menschlicher Leser, eine menschliche Leserin sein; aber es ist sehr gut denkbar, dass es sich bei Rousseaus urtei- 
lender Leserfigur auch um einen göttlichen Leser handelt. Aus seiner Sicht erscheinen die Menschen universalistisch als eine Menschheit, ist der konkrete, sozial, kulturell oder religiös geprägte Mensch ganz essentialistisch der Mensch.

Soviel zunächst zu diesen beiden ersten Absätzen des Incipit. In ihnen wohnen wir der Herausbildung des modernen abendländischen Subjekts bei. Oder anders formuliert: Hier werden Stück für Stück die Grundlagen jenes Vorgangs gelegt, den wir als die Erfindung moderner Subjektivität bezeichnen können. Und es scheint mir nicht unwichtig zu sein, dass dieser Bereich gerade mit dem Leseprozess, mit dem Vorgang des Lesens abgeschlossen oder zugleich eröffnet wird. Denn das moderne Subjekt will sich zu lesen geben, will gelesen werden, als wäre es bereits jenes Subjekt, das auf der Couch des Psychoanalytikers liegt. Oder als wäre es schon jenes Subjekt, das in Italo Calvinos Se una notte d'inverno un viaggiatore gelesen wird (ital. letto) und durch diesen Leseprozess endlich im Bett (ital. letto) vom liebenden Leser geliebt wird. ${ }^{13}$

Im Lesen, in der Lektüre kulminiert die Selbstrepräsentation des Ich. Das moderne Subjekt ist erst im vollen Sinne ein Subjekt, wenn und sobald es zum Objekt einer Deutung, einer Analyse wird. Das Lesen ist in der Tat seit der zweiten Hälfte des 18. Jahrhunderts eine Tätigkeit, die immer weitere gesellschaftliche Bereiche und Sektoren erfasst. Die Alphabetisierungsrate steigt vor allem in der zweiten Hälfte des Jahrhunderts der Aufklärung. Zugleich wird das Lesen zu einem semiotischen Prozess, einem sinnbildenden Prozess, der über das Buch den Menschen, den ganzen Menschen, erfasst und erfassen soll. Das Lesen gleichviel, ob als individuelle oder auch als kollektive Lektüre - wird zu einer immer verbreiteteren Kulturtechnik, zu welcher immer größere Teile der Gesellschaft Zugang haben. Es gibt folglich eine Verbindung zwischen der Erfindung des modernen Subjekt und der Revolution des Lesens, die sich in der zweiten Hälfte des Jahrhunderts der Aufklärung ereignet. ${ }^{14}$

Doch der Vorgang der Lektüre impliziert für das moderne Subjekt noch eine weitere bedeutungsvolle Entwicklung. Denn in derselben Bewegung rückt das Buch auch an die Stelle des Körpers, wird zu jener grundlegenden Metonymie, die es erlaubt, dass die Literatur in der Moderne und für die Moderne zur entscheidenden sinnstiftenden und sinnbildenden Tätigkeit wird. Die Schriftstellerin und der Schriftsteller geben als moderne Subjekte ihre Texte, ihre Bücher so zum Lesen frei, als wären es ihre ureigensten Verkörperungen, ihre Körper-Leiber: Nur wenn Du mich liest, kannst Du mich erkennen - und dies selbstverständlich nicht nur mit dem Verstand, mit dem Intellekt, sondern

13 Vgl. hierzu Ette, Ottmar: LiebeLesen (2020), S. 33-59.

14 Vgl. ebda., S. $93 \mathrm{ff}$. 
auch und gerade mit dem Herzen ... Vergessen wir dabei nicht, dass das Ich mit dem Buch in der Hand vor seinen göttlichen Richter tritt und gleichsam mit seinem Lebensbuch Zeugnis ablegt von jener Aufrichtigkeit und Wahrheit, welche in den Augen des göttlichen Lesers erscheinen mögen!

Nun aber zum dritten und längsten Abschnitt dieses wahrlich famosen Incipit, das uns tief in einige der wesentlichen Veränderungen in der zweiten Hälfte des 18. Jahrhunderts führt, welche am Ursprung unserer Moderne - auch der philosophischen Moderne ${ }^{15}$ - stehen! Wir wollen unser Bild von der Erfindung moderner Subjektivität komplettieren und benötigen dazu noch das weite Feld der literarischen Fiktion.

Denn Jean-Jacques Rousseau greift an dieser Stelle in der Tat auf die Mittel der Fiktion zurück und imaginiert eine denkwürdige Szenerie. Im dritten Abschnitt tritt das Ich dem Höchsten Richter am Tag des Jüngsten Gerichts gegenüber. Wir könnten auch sagen: Das Ich tritt mit dem Buch in der Hand - auf diese Buchmetaphorik, die wir auch in vielen mittelalterlichen Darstellungen des Jüngsten Gerichts immer wieder antreffen, komme ich noch zurück - dem allerhöchsten Leser gegenüber. Denn Gottvater wird zum Leser des Ich, ja muss zum Leser des Ich werden. Er ist am Jüngsten Gericht, aber gewiss auch schon vorher, der „lecteur suprême“, der am Ende seiner Lektüre in den Himmel hebt oder in die Hölle hinabstößt.

Doch werden wir sogleich einer bemerkenswerten Substitution dieses göttlichen Lesers beiwohnen: Denn wir hören die Trompete des Jüngsten Gerichts, vielleicht zugleich aber auch jene Trompete der Fama, des Ruhmes, der so häufig in der allegorischen Darstellungsweise im Abendland mit einer Trompete ausgestattet erscheint. Das Ich präsentiert sich natürlich nicht allein und nackt vor dem Schöpfer, dem Höchsten Richter, sondern erscheint mit dem Buch seines Lebens, mit seinen Confessiones in der Hand. Es tritt selbstbewusst vor seinen Höchsten Richter, sich seiner selbst und des Urteils gewiss, ja sogar davon überzeugt, dass es einen besseren Menschen vor dem Antlitz Gottes nicht geben könne. Deshalb habe dieses Ich auch nicht gezögert, sein eigenes Herz zu enthüllen: „Mon cœur mis à nu“, wie Charles Baudelaire sagen würde.

An die Stelle des Ich, des Körper-Leibs, ist eine Art Ersatz getreten - freilich in der Situation der Verdoppelung. Denn es erscheint das Ich - und das Ich trägt ein Buch, das wiederum auf das Ich verweist, das seinerseits auf das Buch verweist, welches auf das Ich verweist und so weiter: eine Endlosschleife der Verweisungen, in deren Netz sich das moderne Subjekt stets in der Bewegung

15 Vgl. hierzu Habermas, Jürgen: Der philosophische Diskurs der Moderne. Zwölf Vorlesungen. Frankfurt am Main: Suhrkamp 1985. 
und aus der Bewegung konstituiert. Auf diese Weise entsteht eine zirkuläre, sich unendlich spiegelnde Beziehung zwischen ich und Buch, die - so scheint es - jedem Jüngsten Gericht spielend zu trotzen in der Lage wäre. Denn das Objekt des Buches wird zum Subjekt des Ich und umgekehrt.

Das Jüngste Gericht wird in Rousseaus Fiktion unverzüglich entsakralisiert; denn es sind nicht die religiösen, die christlichen Aspekte, die hier vor diesem Gericht im Vordergrund stehen. An die Stelle des christlichen Gottes ist der „souverain“, der „juge“ und vor allem der „souverain juge“ als Ewiges Wesen getreten, als „être eternel“: also ein oberster, souveräner, unbestechlicher, unabhängiger Richter, an dessen Stelle in der sich entsakralisierenden Moderne allzu bald der Kollektivsingular der Geschichte rücken wird. Dieser „souverain juge“ ist bereits auf halbem Wege zwischen dem Thron Gottes und dem Thron der Geschichte, vor dem selbst ein Fidel Castro auftreten und sich inszenieren wird, um sich vor diesem Höchsten Gericht selbst freizusprechen: Ihr niederen Richter könnt mich ruhig verurteilen, „La historia me absolverá“ - die Geschichte wird mich freisprechen! Es ist eine Gerichtsszene, die im Zeichen moderner Subjektivität tausendmal - fiktional wie friktional - imaginiert worden ist

Grundlage seines Gerichtsurteils ist dabei in der Rousseau'schen Fiktion ganz offensichtlich im Wesentlichen das Buch, das Buch - wie wir sagen könnten - des Lebens, die Autobiographie, die durch die Graphie, das Schreiben, selbst (,auto“) das Leben, „bíos“, zeugt. Dieses Buch zeigt alles unverschleiert, nicht verdeckt, in glänzender und ehrlicher Transparenz, ${ }^{16}$ wie es stets Rousseaus Ansinnen und Begehren war. Das Ich verweist auf die Schrift und präsentiert sich selbst, indem es sein Buch präsentiert: „Hier ist, was ich gemacht, hier ist, was ich gedacht, hier ist, was ich war.“ Das Sein - und auch das gewesene Sein - umschließt also das Handeln, das Tun, das „faire“, ebenso wie das Denken, das „penser“: Beides bildet den Menschen, der sich dem göttlichen Urteil präsentiert, sich diesem aber nicht einfach als hilfloses Sujet wie gegenüber seinem Monarchen unterwirft. Nein, das moderne Subjekt unterwirft sich nicht mehr, denn es hat sich schon lange selbst sein Urteil gebildet.

Es geht nicht allein um das Handeln und nicht allein um das Denken, sondern um ein Zusammenwirken im Sein und Geworden-Sein. Das Ich hat als modernes Subjekt eine Geschichte; und es ist Herr über diese Geschichte, weiß sie zu deuten und sein Urteil zu fällen. Kein absoluter Richter, kein absoluter Monarch steht über diesem modernen Subjekt. Wie könnte man hierbei nicht allein

16 Vgl. zur Wichtigkeit der Transparenz im Schreiben des Genfer Schriftstellers die noch immer lesenswerte Studie von Starobinski, Jean: Jean-Jacques Rousseau. La transparence et l'obstacle. Suivi de Sept Essais sur Rousseau. Paris: Gallimard 1971. 
an die Sphäre des Göttlichen und der Religion, sondern auch an die Sphäre des politischen Handelns und der Politik denken? Wäre an dieser Stelle nicht eine Verbindung zwischen der Entstehung moderner Subjektivität und einer politischen Emanzipation gegenüber allen unterdrückenden Mächten herzustellen?

Auch auf diesen Punkt werden wir nochmals - und ebenfalls mit Blick auf die transatlantischen Verbindungen - zurückkommen und insbesondere bei Fray Servando Teresa de Mier die Ausbildung moderner Subjektivität in der Neuen Welt betrachten. Doch kehren wir zurück zum dritten Abschnitt des Incipit der Bekenntnisse Rousseaus! Dieses Sein als ein Geworden-Sein ist im Buch - so wird uns glaubhaft versichert - enthalten: Das Buch und die Schrift rücken an die Stelle des Seins gerade auch in Hinblick auf dessen historische Tiefenschärfe. Und mehr noch: Sie werden zu dessen Legitimierung, zu dessen Rechtfertigung. Das Buch legt Zeugnis ab wie die Märtyrer, die (ein blutiges) Zeugnis ablegen von ihrem Gott; es wird selbst zum unbestechlichen, quasidokumentarischen Zeugnis und zugleich zur Legitimation des Ich vor Gott und den Menschen, die freilich bestenfalls „semblables“ sind, nicht aber wirklich vergleichbar mit dem Ich oder diesem gleichgestellt.

In diesem Zusammenhang erscheint weniger das Schreiben als das Sagen: mehr noch, das Sprechen im Vordergrund zu stehen. Es zählt unverkennbar eine Mündlichkeit, die offensichtlich für den Wunsch der Unmittelbarkeit, der Direktheit, der Unvermitteltheit steht. Das Ziel unmittelbarer, direkter Kommunikation ist von grundlegender Bedeutung für diesen Text und für Jean-Jacques Rousseau; auch diese Ebene hängt mit dem Begehren nach Transparenz zusammen, das Jean Starobinski so klar in den Schriften des „Citoyen de Genève“ herauszuarbeiten vermochte. Doch die direkte, unvermittelte Kommunikation zwischen Autor und Leserin ist eine Zielstellung jeglicher Lektüre, jeglichen Lesens und insbesondere auch der Lesevorgänge in der schon bald heraufziehenden Romantik selbst. Die „franchise“, die Offenheit, das Frei-Heraus, wird zur Grundbedingung dieser direkten, unverstellten Kommunikation, deren Träger das Buch ist. Dabei spielt es keinerlei Rolle, ob es sich um die Darstellung des Guten oder jene des Schlechten im Charakter des Ich handelt: Alles soll mit derselben unvermittelten Wahrheit dargestellt werden. Nichts wird verschleiert! Die Schrift ermöglicht in ihrer nachgebildeten Mündlichkeit eine Lektüre, welche die Direktheit der Verbindung zwischen Rousseau und seinem Lesepublikum sicherstellt. So erst kann sich die moderne Subjektivität unverhüllt zu lesen geben: Vor den Leserinnen und Lesern liegt das Herz des Ich ganz unverhüllt in seiner Nacktheit.

Beschwörend äußert sich das Ich gegenüber seinem Leser, gegenüber seinen „Höchsten Leserinnen und Lesern': Nichts an Bösem sei verschwiegen, nichts an Gutem hinzugefügt worden. Auch an dieser Stelle findet sich wieder die Behaup- 
tung des Unverfälschten, der absoluten Wahrheit, deren Anspruch zumindest in diesem Incipit alles in großer, beeindruckender Radikalität durchdringt. Es handelt sich um einen Text mit totalem, fast totalitärem „truth claim“, der keine abweichende Ansicht, keine anderen Gesichtspunkte erlaubt. Das Ich liegt in seiner ganzen Wahrheit als ein eindeutig zu dechiffrierendes Subjekt vor uns - und es erhebt Anspruch auf diese (s)eine Wahrheit!

Das erzählende Ich räumt die Möglichkeit ein, dass ihn sein Gedächtnis verlassen habe. Das Ornamentale, Ausschmückende komme nur dort vor, wo dem Verfasser eben dies widerfahren sei. Das Gedächtnis des Ich erscheint zwar als unbestechlich, aber nicht als grenzenlos verlässlich und treu. Die Kautelen Rousseaus sind deutlich vernehmbar: An solchen Stellen habe er die Leerstellen ,gefüllt‘. Das Gedächtnis ist gewiss nicht das Archiv, wohl aber jenes lebendige Organ, dem sich das Ich und das Buch vollumfänglich anvertrauen. Zu keinem Zeitpunkt aber sei etwas eingefügt worden, um eine darzustellende Wahrheit zu verfälschen.

Das erzählende Ich tritt hier als sein eigener Zensor auf. Das Falsche sei durch dieses Gedächtnis als das Falsche auch aus dem Buch, aus der Niederschrift der Confessions ausgeschlossen worden. Nicht alles, was das Gedächtnis enthält, ist mithin in das Buch eingegangen; und das Buch selbst enthält mehr, als das Gedächtnis seinerseits enthält. Beide aber werden am Ideal nicht des „vraisemblable“ ausgerichtet, des Wahrscheinlichen oder allem Anschein nach Wahren, sondern an der radikalen Instanz des „vrai“, des absolut und vollständig Wahren. Nur dieser Wahrheit fühlen sich das zeigende wie das erzählende Ich verpflichtet: Bei diesem Buch handelt es sich um eine „confessio“, um ein Bekenntnis oder eine Beichte, bei der niemals das Wahrscheinliche Gegenstand sein kann. Moderne Subjektivität ist dem „truth claim“ verpflichtet.

Daher nun erneut das Zeigen, das „montrer“ und „démontrer“ des Ich: „Ich habe mich gezeigt, so wie ich war.“ In diesem Satz erscheint nochmals deutlicher die Gespaltenheit des Ich als ein Zeigendes und zugleich Gezeigtes und, damit einhergehend, die temporale Verschiedenheit von „je“ und „moi“. Das zeigende Ich zeigt auf, was am gezeigten Ich an Wahrheiten aufzuzeigen ist. Es nimmt für das gezeigte Ich ein Bekenntnis vor, ja setzt eine Beichte in Gang. Die damit einhergehende Verdoppelung, das Doppelt-Sein der beiden fundamentalen Ich-Figuren, ist zugleich das von Schreibendem und Lesendem, von Sich-Selbst-Schreibendem und Sich-Selbst-Lesenden, welcher sich als Schreibender und als Schreibenden selber liest und einer genauen Lektüre unterzieht. Dies erfolgt in der Form einer Prüfung: Das Ich habe sich als verachtenswert und schlecht (zwei Adjektive) gezeigt, wenn es dies gewesen sei, und als gut, großzügig und erhaben (drei und damit mehr Adjektive), sobald dies der Fall gewesen sei. Das moderne Subjekt weiß, dass ihm Vergebung und Absolution zustehen, ja mehr noch - eigentliche Bewunderung! 
An dieser Stelle tritt eine Dimension des Erhabenen, des Sublimen mit in den Diskurs, die uns noch später beschäftigen wird, auf die ich hier aber bereits aufmerksam machen will. Denn das Sublime, das Erhabene, wird zu einer das 19. Jahrhundert prägenden Kategorie, welche freilich schon im Kontext der Landschaftsbeschreibungen der Empfindsamkeit auftaucht und in den verschiedensten Künsten ihren angemessenen Ausdruck zu finden sucht.

An die Stelle des Zeigens, des „montrer“, tritt jetzt die Metaphorik des Aufdeckens, des Enthüllens, des „dévoiler“, der Entschleierung aller Gegenstände, um die vollkommene Transparenz zu erreichen. Jean Starobinski hat in der bereits erwähnten denkwürdigen Folge von Studien diese Bedeutung des Schleiers enthüllt und auf die Wichtigkeit der Transparenz für Jean-Jacques Rousseau hingewiesen, ein Begehren nach Transparenz, das wir später in Rousseaus Briefroman Julie ou la Nouvelle Héloïse vorfinden werden. Hier ist also jener Ausdruck und jene Formel zu sehen; auf die - wenn auch in anderem Kontext - noch ein Charles Baudelaire zurückgreifen wird, wenn er von „Mon cœur mis à nu“, meinem gänzlich entschleierten und nackten Herzen sprechen wird. Auch eine Juana Borrero wird sich auf die Flüssigkeit ihres Herzens verlassen, um ihrem Liebhaber ihre Absichten vollständig transparent vor Augen zu führen. Denn der Schleier wird weggezogen; und das Ich erscheint so, wie es vor den Augen seines Schöpfers, des Schöpfers aller Dinge erscheint. Denn der Creator taucht in dieser Passage als unmittelbarer Gesprächspartner auf und rückt in den Blick des Lesepublikums als oberste Instanz, deren Urteil jedoch vom zeigenden Ich vorweggenommen wird. Denn es hat sich bereits in seiner Größe und Unschuld gezeigt.

Mit dieser Geste, mit dieser Einbeziehung ist damit neben den Leser, neben das menschliche Lesepublikum, eine Art Überleser getreten, das „être suprême“, das oberste Wesen, das im Grunde alles schon weiß, aber an dieser Stelle nun zum doppelten Leser des Ich wird. Das Ich ist bereits durch seine Geschichte freigesprochen und kommt am Tage des Jüngsten Gerichts zu jenen, die bei Gott im Himmel sind. Doch das Innere des Ich wird nach außen gekehrt: Es kommt eine Dynamik ins Spiel, die das Innere als Bedingung des Zeigens und des Schreibens auf ein Äußeres bezieht, das demgegenüber abgewertet wird. An die Stelle des Äußeren, des Schleiers, tritt das De-Voilierte, das Ent-Hüllte, das seiner Hülle Entkleidete, oder anders: das Wahre, das Wahrhaftige, das nackt erscheint!

Dies bedeutet keinesfalls, dass die Oberfläche, die nackte Außenhaut, vorherrschen würde, ganz im Gegenteil: Durch die Bekenntnisse kommt ja gerade das Innere nach außen und gibt so die Tiefe dem erkennenden Blick preis. Wir haben es folglich sehr wohl mit dem Inneren und mit der Tiefe des Ich zu tun: sie bilden die Grundlage für die Erkenntnis, für die Wahr-Nehmung der Wahrheit des modernen Subjekts. Denn die Wahrheit des modernen Subjekts liegt nicht in seiner Oberfläche, sondern in der Tiefe - ganz so, wie der Psychoanalytiker von der Oberfläche 
des Manifesten zur Tiefe und Latenz vordringen muss, um das Ich - im Verbund mit dem Es und dem Über-Ich - in seiner Ganzheit erkennen zu können.

In diesem Teil des Incipit stoßen wir auf eine Topik, die auch eine Topographie beinhaltet, und die dem Verborgenen, dem Tiefen, dem in der Tiefe Befindlichen die eigentliche Wahrheit zuschreibt. Die Oberfläche kann uns täuschen, die Tiefe tut dies nicht. Dies entspricht noch dem Umgang der Psychoanalyse Sigmund Freuds mit dem modernen Subjekt: Sie sucht und findet ihre Wahrheit und Erkenntnis nicht im Manifesten, nicht in dem an der Oberfläche Befindlichen, sondern im Verborgenen, Tiefen und Aufzudeckenden, zu Enthüllenden. Die Psychoanalyse sucht die Wahrheit in der Latenz: Sie geht von einer modernen Subjektivität aus, wie sie Les Confessions von Jean-Jacques Rousseau Stück für Stück aufbauen. Dies bedeutet nicht, dass Rousseau der Erste oder der Einzige gewesen wäre: Doch er hat in seiner gattungsbegründenden Schrift wie kein anderer die Grundlagen moderner Subjektivität auf den Punkt gebracht.

Bemühen wir noch einmal die Psychoanalyse Sigmund Freuds, die in ihrer epistemologischen und symbolischen Ordnung ebenso für die Moderne wie für die Form einer modernen europäischen Subjektivität einsteht! Sie ist ein Vordringen in die Tiefe, vom Manifesten zum Latenten, vom Bewussten ins Unbewusste, das die Tiefen des Es erreicht und Stück für Stück dem Ich zugänglich macht. Für Freuds psychischen Apparat bedeutet dies: Wo Es war, muss Ich werden. Sie verstehen jetzt vielleicht ein wenig besser, warum die Psychoanalyse von sich aus stets autobiographisch sein muss, den Analytiker also miteinbezieht und miteinbeziehen muss. Der Analytiker ist der Leser der Tiefe. Das in der Tiefe Gefundene ist wahrer als das, was wir an der Oberfläche vorfinden. Das postmoderne Denken wird in der zweiten Hälfte des 20. Jahrhunderts versuchen, diese Beziehung, diese Topik zu verändern, umzudrehen, um der Oberfläche ihren Rang, ihre Erkenntnis- und Sinnhaftigkeit zurückzugeben. Dies bedeutete freilich nicht, dass sie der modernen Subjektivität, ja noch nicht einmal der Subjektivität in der Moderne ein Ende setzte.

Vor diesem hier breit ausgefalteten Hintergrund überrascht es nicht, dass Jean-Jacques Rousseau schon wenige Seiten später in seinen Confessions gerade dem Lesen, der Lektüre eine überaus wichtige Rolle bei der Herausbildung von Subjektivität sowie gleichzeitig für seinen eigenen Entwicklungsgang und Lebensweg zuschreibt. Die Lektüre wird - auf den nachfolgenden Seiten von Les Confessions wie auch anderer Schriften Rousseaus - zu einem bevorzugten und privilegierten, wenn auch nicht unkritisch wahrgenommenen Mittel und Vehikel der eigenen Entwicklung des Ich. Letzteres liest sich selbst als Schreibendes und sich Entwickelndes: Es ist sein eigener Leser.

Bei aller Kritik und bei aller Einsicht in die Gefahren der Lektüre überwiegt doch deutlich eine positive Sichtweise darauf als beschleunigender Kraft bei 
der Herausbildung des Menschen im eigentlichen Sinne. Das Lesen vervielfacht die Möglichkeiten der komplexen Entfaltung eines modernen Subjekts. Nehmen wir uns also ein zweites Zitat vor, das sich nur wenige Seiten nach dem Incipit der Confessions findet.

Ich fühlte, bevor ich dachte: Dies ist das allgemeine Schicksal der Menschheit. Ich empfand mehr als ein Anderer. Ich weiß nicht, was ich bis zum Alter von fünf oder sechs Jahren machte; und ich weiß nicht recht, wie ich lesen gelernt; ich erinnere mich lediglich an meine ersten Lektüren und an ihre Wirkung auf mich: Dies ist der Zeitpunkt, von dem an ich ein ununterbrochenes Bewusstsein meiner selbst herleite. Meine Mutter hatte mir Romane hinterlassen. Mein Vater und ich machten uns daran, sie nach dem Abendessen zu lesen. Es ging zunächst nur darum, mich durch amüsante Bücher an die Lektüre zu gewöhnen: Aber bald schon war das Interesse an ihnen so lebendig, dass wir sie Buch für Buch ohne Unterlass lasen und alle Nächte mit dieser Beschäftigung zubrachten. Wir konnten niemals damit aufhören, bevor wir nicht das Ende erreicht hatten. Bisweilen, wenn mein Vater des Morgens die Schwalben hörte, sagte er ganz schuldbewusst: Gehen wir zu Bett; ich bin kindlicher noch als du.

Innerhalb kurzer Zeit erlernte ich mit Hilfe dieser gefährlichen Methode nicht nur eine hohe Fähigkeit des Lesens und mich Verstehens, sondern eine für mein Alter einzigartige Intelligenz für die Leidenschaften. Ich besaß keinerlei Vorstellung von den Dingen, als mir schon längst alle Gefühle vertraut waren. Ich hatte noch nichts gesehen, aber schon alles gefühlt. Diese konfusen Gefühlsbewegungen, die ich Zug um Zug empfand, entstellten keineswegs den Verstand, den ich noch nicht besaß; aber sie unterrichteten mich von einem ganz anderen Schlage, und sie vermittelten mir vom menschlichen Leben bizarre und romaneske Begriffe, von denen mich Erfahrung und Reflexion niemals mehr gänzlich geheilt. ${ }^{17}$

Wir stoßen in dieser Passage zum Erlernen des Lesens auf einen Leser, der ähnlich wie Italo Calvinos Gian dei Brughi in Il Barone rampante mit dem Lesen nicht mehr aufhören kann und gemeinsam mit seinem Vater pausenlos Buch um Buch verschlingt. Es gibt vor allem in der zweiten Hälfte des 18. Jahrhunderts vielfach Indizien für diese Art atemloser Lektüre, die nicht aufhören kann, bevor das Ende eines Buchs erreicht ist. Diese Leidenschaft des Lesens prägt alle Gefühle vor: Wir erlernen die Liebe ganz so, ${ }^{18}$ wie wir Lesen, Schreiben und Rechnen erlernen und malen uns unsere Gefühle aus, noch bevor wir sie auf die Außenwelt richten. Wir lernen zu lieben, noch bevor wir uns erstmals verlieben. Wir stoßen hier auf eine Figur des Lesens und zugleich auf eine Leserfigur, wie sie in der Literatur aus dem 18. Jahrhundert oder über das Jahrhundert der Aufklärung sehr präzise beschrieben worden ist. Bei Jean-Jacques

17 Rousseau, Jean-Jacques: Les Confessions, S. 4.

18 Dies ist eine der Hauptthesen der Vorlesung von Ette, Ottmar: LiebeLesen (2020). 
Rousseau ist diese Selbstzeichnung dabei mit deutlich aufklärerischer Kritik ausgestattet.

Wir begreifen anhand des obigen Zitats vielleicht prägnanter, in welchem Maße im Sinne Rousseaus die Subjektwerdung, der Prozess der eigentlichen Bewusstwerdung des Ich gegenüber sich selbst, mit der Erfahrung des Lesens verknüpft ist oder verknüpft wird. Lesen ist einer der wichtigsten Nährstoffe moderner Subjektivität. Denn es bleibt nicht ohne längerfristige Auswirkungen auf das Ich: Lesen formt das Ich in seinem Werdegang. Um es auf eine bekannte Formel moderner Subjektwerdung zu bringen: Sag' mir, was du liest, und ich sage Dir, wer du bist!

Dabei ist bei Rousseau entscheidend, das sich dieses Lesen der Bücher aus der Bibliothek der Mutter zunächst auf Romane richtet, welche das Ich gemeinsam mit seinem Vater liest oder vielleicht besser noch verschlingt. Diese gemeinsame Lektüre ist eine „lecture à voix haute“, also keine leise, sondern eine laute Lektüre, wobei sich die beiden jeweils abgewechselt zu haben scheinen. Wir haben es an dieser Stelle mit einem deutlichen Verweis auf jene Revolution des Lesens zu tun, die im Verlauf des 18. Jahrhunderts stattfand; und die gebildete Schicht der Uhrmacher mag in Genf auf besondere Weise dafür soziologisch einstehen.

Zugleich manifestiert sich in dieser Passage eine ausgeprägte und weiter wachsende Lesewut, die gleichsam nächtelang von beiden in einer Art kindlicher Euphorie und kindlicher Lektüre ausagiert und befriedigt wird. Nicht umsonst bemerkte Roland Barthes in $S / Z$, dass nur die Professoren, die Alten und die Kinder Bücher mehrfach läsen. Längst geht es nicht mehr um das Lesen-Lernen, denn rasch hat die Lektüre selbst auf das Leben übergegriffen: Lesen ist lebensverändernd oder kann dies doch zumindest sein. Das erzählende Ich zeigt in Les Confessions am Beispiel des erzählten Ich aus großer zeitlicher Distanz, dass sich dies schon sehr früh auf die affektive Ökonomie des Ich, auf die Art und Vielfalt seiner Gefühle auswirkte.

Das Lesen-Lernen mit Hilfe dieser - wie der Verfasser der ersten modernen Autobiographie schreibt - gefährlichen Methode bringt auch Veränderungen mit sich, die unbeabsichtigt sind. Denn eine überreiche Gefühlswelt wird angelegt, welche die affektive Ausstattung anderer Menschen weit übertrifft. Im Zentrum der Romane steht ein Wissen um die Leidenschaften; und diese einzigartige Intelligenz, die das ich in diesen Dingen entwickelt, ist nicht auf eine Erfahrung in der textexternen Welt zurückzuführen, sondern geht allein auf die gemeinsam gelesenen Romane zurück. Ihre Fiktionen verwandeln sich in lebendige, zugleich erlebte und gelebte Realität. Das Ich wird so schon bald zu einem Experten nicht in den Dingen („les choses“), sondern in den Worten („les mots“), weiß über all das Bescheid, was im eigenen Leben außerhalb des Lesens noch nicht erfahren 
werden konnte. Fiktionalität geht als zentrales Element in Realitätserfahrung mit ein: Die Wirklichkeit moderner Subjektivität ist weit davon entfernt, allein von einer textexternen, außersprachlichen Realität gebildet zu werden.

Auf diese Weise prägt dieses Lesen dann auch die späteren Erfahrungen im Leben, prägt die Wahrnehmung wie die Reflexion über Vorgänge und Erfahrungen, die doch immer aller Rationalität und Vernunft zum Trotz von den Leseerfahrungen anstelle der Lebenserfahrungen ausgerichtet werden. Das Lebenswissen der Romane, die Vater und Sohn in der Bibliothek der verstorbenen Mutter finden, wird gleichsam auf das Leben selbst direkt und unvermittelt bezogen, das Lesen also mit dem Leben kurzgeschlossen. Wir wissen alle, was daraus entstehen kann - Rousseau spricht nicht umsonst von der Gefährlichkeit dieser Methode, Lesen zu lernen. Auch bei dem Genfer Bürger wird ein Warntäfelchen aufgestellt: Vorsicht, Lesen ist gefährlich! Lesen bildet das Leben und Fiktion ist von Realität nicht einfach abzutrennen: Sie konfiguriert unsere Realität.

Auch wenn der ,Archileser‘ Gott, wenn der göttliche Leser noch immer im Hintergrund schlummern könnte - ein schläfriger Gott, der nur von Zeit zu Zeit in die Bücher seiner Menschen schaut: Entscheidend ist doch, was der irdische Leser, die irdische Leserin in Rousseaus Bekenntnissen liest. Und jenseits aller Werke und Schriften, die der Schriftsteller Jean-Jacques Rousseau vom Leser Rousseau sich berichten und auflisten lässt, zeigt sich hier doch deutlich, dass es im Grunde ohne den Prozess des Lesens bei Rousseau eine völlig andere Entwicklung des Lebens gegeben hätte. Es wäre wohl unwahrscheinlich, dass wir jemals mit einem Schriftsteller namens Rousseau in Berührung gekommen wären, hätte es diese Lesewut, dieses nächtelange gemeinsame Verschlingen von Büchern, welche die Mutter hinterließ, nicht gegeben. Denn zum einen ist das Lesen für den Schriftsteller und Philosophen noch immer mit der Utopie der Direktheit gekoppelt: Literatur als Kommunikation, aber mehr noch Literatur als Lebenswissen. Es handelt sich um jenes Wissen, welches das Leben von sich selbst hat und uns als Schreibenden in die Feder und als Lesenden ins Ohr diktiert. Und zum anderen ist es das Vermächtnis der bei der Geburt des Ich verstorbenen Mutter: Sie stillt und nährt den Knaben noch mit Hilfe ihrer Bücher. Diese mütterliche Hinterlassenschaft kann in ihrer Wirkung gar nicht überschätzt werden.

Rousseau hat nicht nur Kritik an seiner frühen Lektüre von Romanen geübt, welche seine Mutter einst gesammelt und gelesen hatte, sondern er hat sich selbst auch als Romanschriftsteller erprobt. Und dies tat er mit einem gewaltigen Erfolg: Rousseau hat einen wahren Bestseller des 18. Jahrhunderts verfasst, der zu einem Klassiker der Liebesliteratur geworden und aus den Bücherschränken der nachfolgenden Jahrhunderte kaum wegzudenken ist. Dabei hat die Liebeskonzeption, welche Rousseau in seinem Roman über eine fundamentale Drei- 
ecksbeziehung verfasste, stark auf das Verständnis der Liebe im 19. Jahrhundert gewirkt. Doch bleiben wir an dieser Stelle im Jahrhundert der Aufklärung!

Jean-Jacques Rousseau ist unter den wahrlich großen Figuren des 18. Jahrhunderts zweifellos der für die Moderne wohl folgenreichste Philosoph, in jedem Falle aber jener Kopf, der zusammen mit sehr wenigen anderen aus dem Jahrhundert der Aufklärung dauerhaft herausragt. Sein literarisches wie sein philosophisches Erbe lassen sich kaum überblicken. Und zu seinen wichtigsten Hinterlassenschaften zählt der Entwurf der modernen Autobiographie und die damit zutiefst verbundene Entfaltung einer modernen Subjektivität, die trotz aller Umgestaltungen auch in den ersten Jahrzehnten des 21. Jahrhunderts aller postmodernen Unkenrufe zum Trotz - nichts von ihrer grundlegenden Bedeutung verloren hat.

Lassen sie mich an dieser Stelle die „entreprise“, die autobiographische Unternehmung des Jean-Jacques Rousseau, über Les Confessions hinaus ein wenig weiterverfolgen und zu einem Buch kommen, das für den „Préromantisme“ sowie für die europäische wie außereuropäische Romantik von großer Bedeutung war. Ich spreche von Les Rêveries du promeneur solitaire, die der in Genf geborene Schriftsteller zwischen 1776 und 1778 in Paris und Ermenonville verfasste, wo Rousseau am 2. Juli desselben Jahres verstarb.

Dieses kleine und unabgeschlossene literarische Werk fällt also in die allerletzte Schaffenszeit des Genfer Literaten, geht aber auf Aufenthalte auf der St. Petersinsel im Bieler See, gar nicht so weit vom Genfer See entfernt, zurück; eine Landschaft, in der ich mich selbst recht oft aufgehalten habe und die mir rund um die Presqu'île de Saint-Pierre etwas ans Herz gewachsen ist. Selbstverständlich - und ich räume dies sofort ein - habe ich auch in dieser Landschaft zum ersten Mal die Rêveries gelesen, diese Träumereien des einsamen Spaziergängers. Hier also hielt sich Rousseau wiederholt im Jahre 1765 auf und legte in einer an Verfolgungen unterschiedlichster Art recht reichen Phase seines Lebens die Grundlagen für ein gelungenes Ausklingen seines autobiographischen Vorhabens, dessen Schlusspunkt wir uns nun etwas näher anschauen wollen.

Das Werk ist in verschiedene Spaziergänge, in verschiedene Promenades eingeteilt; es ist unumgänglich, Sie auch bei diesem Werk zunächst mit dem Incipit zu konfrontieren, weil dieses den Ton vorgibt und Ihnen vielleicht nochmals näherbringen kann, warum ich Rousseau als den vielleicht ersten der unglücklichen Schriftsteller bezeichnete:

So bin ich denn alleine auf der Erde und habe keinen Bruder, keinen Nächsten, keinen Freund, keine Gesellschaft außer mir selbst. Der soziabelste und liebendste der Menschen wurde auf einstimmigen Beschluss hin daraus verbannt. In allen Verfeinerungen ihres Hasses haben sie gesucht, welche Folter für meine empfindsame Seele am grausamsten 
wäre, und sie haben gewaltsam alle Bande zerbrochen, die mich mit ihnen verbanden. Ich hätte die Menschen geliebt, ihnen selbst zum Trotze. ${ }^{19}$

Vom ersten Satz an ist die Einsamkeit des Ich absolut - zumindest in dessen literarischer Inszenierung. Niemand mehr wünscht in Kontakt mit diesem Ich zu sein, bei dem nun erzählendes und erzähltes, zeigendes und gezeigtes Ich zeitlich sehr nahe beieinander liegen. Die Selbsteinschätzung des Ich als höchst soziabel, die Gesellschaft anderer Menschen suchend, ist ein Selbstbild, das in krassem Widerspruch zur sozialen Ausgeschlossenheit des Ich steht. Die gesamte Passage ist von schroffen Gegensätzen gekennzeichnet: Dem Ich stehen die Anderen, der Liebe steht der Hass, der Gesellschaft und Gemeinschaft steht die radikale Einsamkeit gegenüber. Dabei haben sich die ,Anderen' gegen das Ich verschworen, haben eine Front gegen das Ich aufgebaut, um es von aller Kommunikation auszuschließen und zu quälen.

Haben wir es von Beginn an mit einer Paranoia, mit einem Verfolgungswahn des Ich zu tun? Auf den ersten Blick will es so scheinen. Doch in der Tat war Rousseau aus der Gruppe der französischen Aufklärer ausgebürgert worden, hatte sich mit seinem früheren Freund Denis Diderot überworfen, war aus der Gemeinschaft der Encyclopédistes gestoßen worden, hatte den Spott eines Voltaire auf sich gezogen, kurz: Er war zu einem der berühmtesten Ausgestoßenen des Aufklärungszeitalters geworden. Wir werden später noch sehen, dass er auf Grund seines schlechten Renommees selbst den Hohn und Spott von Menschen auf sich zog, die ihn im Grunde gar nicht kannten, die ihm als ,Outcast‘ aber begegnen und über ihn lachen wollten.

Doch zugleich ist es auch die literarische Inszenierung einer Einsamkeit, die sich im Projekt seiner Bekenntnisse mit der Formulierung der eigenen radikalen Außergewöhnlichkeit und des „moi seul“ bereits angedeutet hatte. Solle es doch nur einer der anderen Menschen wagen zu behaupten, er sei besser als dieser eine Mensch mit Namen Jean-Jacques Rousseau! Derartige Formulierungen deuten an, warum das Ich in Les Rêveries du promeneur solitaire aus einer literarischen Logik heraus zum Solitär werden musste. Und diese gesellschaftliche Rolle innerhalb einer feudalistischen Ständegesellschaft des Ancien Régime durchdachte der Genfer Bürger wie kein anderer vor ihm. Auch hierin kommt die Radikalität und Kompromisslosigkeit Rousseaus zum Ausdruck.

Das in zehn ungleich lange „Spaziergänge“ eingeteilte und im Jahre 1782, also nach Rousseaus Tod, veröffentlichte Werk knüpft an Les Confessions an, verlagert den Schauplatz des Geschehens aber von der Außenwelt noch stärker

19 Rousseau, Jean-Jacques: Les Rêveries du promeneur solitaire. In (ders.): Collection complète des œuvres de J. J. Rousseau, 17 Bde. Genf 1782, Bd. 10: Les Confessions, S. 369. 
in die Innenwelt eines Ich, das seiner Leserschaft nicht nur die eigene Seinsweise, sondern auch die eigene Sichtweise der Welt näherbringen will. Dieses Schreibprojekt entfernt sich daher noch weiter von der Gattung der Memoiren, als es bereits Les Confessions tat. Folgerichtig enthalten die Rêveries damit eine Vielzahl zwischen Literatur und Philosophie oszillierender Betrachtungen, welche in die Form von Spaziergängen gekleidet sind, eine literarische Form, die sich seit der Antike beobachten lässt, aber auch in einem so anderen Geist wie Friedrich Nietzsche ihren äquivalenten philosophisch-literarischen Ausdruck gefunden hat.

Les Rêveries du promeneur solitaire sind von ihrer ersten Zeile an ein literarisches Dokument der Introspektion, einer Abkehr von der Gesellschaft, in welcher der Philosoph nichts mehr zu gewinnen hat, und einer Innerlichkeit, welche den Ton für den Individualismus wie den Rückzug aus der Gesellschaft der nachfolgenden Generation der Romantiker vorgeben wird. Das Incipit eröffnet damit nicht den Weg in eine Verzweiflung am eigenen Ausgestoßen-Sein, sondern die Wege in eine Innerlichkeit, in welcher der Schriftsteller seinen Frieden mit der Welt machen wird.

Dafür aber ist der räumliche Kontext, die landschaftliche Umgebung des Ich, sein Habitat von allergrößter Bedeutung. Hier kommt die Landschaft am Bieler See zum Zuge, an deren Ufern sich nicht nur die Stadt Biel beziehungsweise Bienne, sondern das damals noch zu Preußen gehörige Neuchâtel ansiedeln. Weit von diesen städtischen Agglomerationen entfernt befindet sich die St. Petersinsel an der südlichen Seite des langgestreckten Sees. So heißt es gleich zu Beginn der fünften „Promenade“, also im Zentrum dieses Werks, an dem Rousseau noch in den letzten Wochen vor seinem Tode schrieb:

Unter allen Wohnungen, wo ich geweilt (und ich hatte wirklich charmante), hat mich keine so wahrhaft glücklich gemacht und weckt so zärtliche Erinnerungen wie die St. Petersinsel inmitten des Bieler Sees. Diese kleine Insel, welche man in Neuchâtel die Ile de La Motte nennt, ist wenig bekannt, selbst in der Schweiz. Meines Wissens hat kein Reisender sie jemals erwähnt. Und doch ist sie sehr angenehm und einzigartig gelegen für das Glück eines Menschen, der sich zu beschränken sucht; Denn obwohl ich vielleicht der Einzige auf der Welt bin, dem sein Schicksal zu einem Gesetz geriet, kann ich nicht glauben, der Alleinige zu sein, der einen so natürlichen Geschmack besitzt, wenngleich ich einen solchen noch bei keinem anderen fand. ${ }^{20}$

Wir erkennen ohne weiteres das Beharren auf der eigenen Einzigartigkeit wieder, das bereits Les Confessions auszeichnete, und sehen es an dieser Stelle verbunden mit der Einzigartigkeit eines Ortes, der selbst den Schweizern nicht

20 Rousseau, Jean-Jacques: Les Rêveries du promeneur solitaire, S. 434. 
bekannt zu sein scheint. Zwar wird die „Insula Comitum“, die „Grafeninsel“, bereits 1107 erwähnt und geht als Schenkung an das Kloster Cluny durch Wilhelm III. von Burgund-Mâcon, doch erwähnt Rousseau das ehemalige Cluniazenser-Priorat nicht, um die Einsamkeit der von ihm gewählten landschaftlichen Szenerie nicht zu stören und seine Verbundenheit mit der Natur zu betonen.

Denn letztere spielt eine überragende Rolle nicht nur in den philosophischen, sondern auch in den autobiographischen Reflexionen des einsamen Spaziergängers, der sich als Botaniker betätigt. In seiner Nachfolge werden sich ganze Heerscharen von Amateur-Botanikern auf die Wiesen und in die Wälder begeben, um mit ihrer Botanisiertrommel jenes Glück und jenen Seelenfrieden einzusammeln, von dem der Genfer Bürger sprach. Sehen wir uns hierzu den Ausgang der siebten „Promenade“ einmal näher an:

Es ist die Kette an zugehörigen Ideen, die mich mit der Botanik verbindet. Sie versammelt und erinnert in meiner Einbildungskraft alle Ideen, die ihr so sehr schmeicheln. Die Wiesen, die Gewässer, die Wälder, die Einsamkeit, der Frieden vor allem und die Ruhe, die man inmitten all dessen findet, werden von ihr ohne Unterlass meinem Gedächtnis eingraviert. Sie lässt mich die Verfolgungen der Menschen, ihren Hass, ihre Verachtung, ihre Unverschämtheiten und alle Übel vergessen, mit der sie meine zärtliche und ehrliche Bindung an sie vergolten haben. Sie bringt mich an friedliche Wohnsitze, wo einfache und gute Menschen wie etwa jene weilen, mit denen ich einstens gelebt habe. Sie erinnert mich an meine Jugendzeit und an meine unschuldigen Freuden, sie lässt mich alles noch einmal genießen und macht mich sehr häufig noch inmitten des traurigsten Schicksals glücklich, das jemals ein Sterblicher erlitt. ${ }^{21}$

Das Bild des botanisierenden Rousseau hat sich allen Leserinnen und Lesern eingeprägt und verbindet sich mit der Landschaft um den Lac de Bienne und die St. Petersinsel, in welcher sich diese Träumereien bevorzugt ansiedeln. Die Botanik steht für die intensive Beschäftigung mit einer Natur, welche nicht etwa die Natur der Tropen, sondern eine Natur in den gemäßigten Zonen ist, wo das erzählende Ich für uns eine Landschaft mit Wäldern und Hügeln, mit Seen und Bächlein, mit Wiesen und Wegen aufbaut, die ohne Zweifel dem idyllischen Register und einem locus amoenus entnommen sind. Jean-Jacques Rousseau ruft aus einer langen literarischen Tradition Landschaftselemente auf, die in den erzählenden Texten einer nachfolgenden romantischen Generation nicht mehr fehlen dürfen.

Diese intensive Beschäftigung mit der Natur versöhnt das Ich mit seiner eigenen Geschichte, lässt die ältesten Spiele und Freuden wieder lebendig werden, blendet all das aus, was das Ich an Verfolgungen hat erleiden müssen, lässt all das vergessen, was von Seiten der Kultur eine gute, friedvolle und ruhige

21 Ebda., S. $480 \mathrm{f}$. 
Natur niederzudrücken sucht. Die Botanik eröffnet so das Tor zur Natur, die dem Ich all das wiederzugeben scheint, was durch die Natur dem leidenden Menschen genommen ward: die Ruhe, die eine Seelenruhe ist, und der Frieden, der sich aus der Verbindung mit der Natur nährt. In einer solchen Landschaft sind auch die Menschen einfach und gut, ganz wie das Ich selbst. Das Reich der Botanik führt zu einer Natur, die den Menschen in ihre Arme schließt und ihn von den Bedrückungen durch eine ständig zerstörerische und hasserfüllte Kultur erlöst, mit der die Zeitgenossen und die zeitgenössische Ständegesellschaft das Ich verfolgen.

Gegen diese das Ich umkreisende und verfolgende Gesellschaft errichtet sich das Bollwerk moderner Subjektivität, konstituiert sich das Ich aus einem Dagegen, das einer Kultur zivilisatorischer Verfeinerung ebenso gilt wie einer Welt, in welcher die „philosophes“ die Welt nur immer neu interpretieren. Es kommt aber darauf an, das Ich aus dieser zivilisatorischen Umlagerung zu befreien und zu seiner Ruhe, zu seinem Seelenfrieden zu führen - zu seiner Erlösung und Erfüllung, wie es Rousseaus Träumereien hier andeuten. Auch hierin ist ein Stück weit jenes Begehren der Transparenz und jene inständig erhoffte Transparenz des Sinnes zu erkennen, nach der sich der Genfer Bürger immer stärker sehnte.

Die scharfe Opposition zwischen Subjekt und Gesellschaft schafft an solchen Stellen vor allem den Raum, um dem modernen Ich Platz für die eigene Entwicklung und Ausprägung zu geben: gegen die Gesellschaft, gegen die Zivilisation, gegen die Anderen. Nehmen wir die Aufspaltung des Ich in verschiedene Ichs, also die Vervielfachung von Ich-Positionen, zusammen mit dieser Frontstellung des Ich gegenüber allem und allen anderen, die von ,außen` das Ich umgeben, so sehen wir leicht, dass die Emanzipation und Individuation moderner Subjektivität nicht notwendig mit einem gesteigerten Glücksgefühl dieses Subjekts einher geht. Zumindest ist diese Gefahr gegeben: Und das Beispiel des Ich in Les Confessions sowie in Les Rêveries du promeneur solitaire zeigt diese Möglichkeit schonungslos auf.

Welche Heilmittel können an diesem wunden Punkt moderner Subjektwerdung in Stellung gebracht werden? Wie lässt sich dieser neuen Positionalität des modernen Subjekts in ihren negativen Konsequenzen entgegenwirken? Wie also kann sich das in Bedrängnis geratene Subjekt Hilfe und Heilung verschaffen? Die Antwort Rousseaus auf all diese Fragen und Verunsicherungen ist der Verweis auf die Natur.

Denn das Ich muss sich endlich mit der Natur versöhnen, muss die Kluft überwinden, welche es von der Natur so schmerzhaft trennt. Den Königsweg dafür, so schreibt Jean-Jacques, biete die Botanik, jenes Sammeln und Ordnen eines Sinnes, den die Natur selbst vorgibt und der dem Botaniker unmittelbar 
und unvermittelt vor Augen tritt. Wir müssen also wieder lernen, im Buch der Natur $^{22} \mathrm{zu}$ lesen und aus dieser Lektüre stärkende Kräfte zu ziehen. Rousseau knüpft auf diesem Weg an die sich zeitgenössisch stark entwickelnde Botanik an. Und doch kann das Ich trotz aller Anstrengungen die Verfolgungen und alle Verwundungen, welche ihm diese Gesellschaft beigebracht hat, nicht vergessen und nicht leicht verwinden. Die Versöhnung mit der Natur - denken Sie in heutiger Zeit etwa an das sogenannte ,Waldbaden' und an die Umarmung von Bäumen - ist ein Prozess, den das Ich Schritt für Schritt lernen muss; ein Prozess, der das Ich näher an die Natur heranführen soll. Der kurze Vergleich mit unserer heutigen Zeit, in der selbst Politiker wie der aktuelle bayerische Ministerpräsident sich beim Umarmen von Bäumen ablichten lassen, sollte Ihnen zeigen, dass die Vorstellungen Rousseaus von uns Heutigen so schrecklich weit nicht entfernt sind.

Damit aber nimmt das moderne Subjekt eine hochgradig autoreflexive und zugleich von vielen Seiten bedrohte Positionalität ein. $\mathrm{Zu}$ jedem Zeitpunkt muss sich dieses Subjekt vergewissern, in welcher Beziehung es nicht allein zu anderen Menschen steht, sondern wie seine Relationen mit der Kultur und mit der Natur, mit Gesellschaft und Gemeinschaft geprägt sind. Es sind diese Überlegungen und Reflexionen, welche ebenso das gezeigte wie vor allem das zeigende Ich charakterisieren und damit eine Landschaft formen, die man - und dies keineswegs nur mit Blick auf den Topos des locus amoenus - sehr wohl als eine Seelenlandschaft bezeichnen kann. Denn die innere Seele des Ich findet und weiß sich eins mit dieser Landschaft der Natur, mit dieser Landschaft der Theorie, ${ }^{23}$ die das Ich in der Art und Weise, wie es über sich nachdenkt, sukzessive geschaffen hat.

Dazu gehört das verschärfte Sinnieren über die glückliche Gemeinschaft und ihre Feinde. Jean-Jacques Rousseau gibt diesem Nachdenken seiner IchFiguren in Les Rêveries du promeneur solitaire ungeheuer viel Raum. Dieser Raum der Selbstreflexion, des Nachdenkens, der Meditation, des Tagtraums macht das Spezifische dieses Bandes aus Rousseaus letzten Lebensjahren aus. In ihm sind schon die romantische Aufwertung des Traums und die Öffnung gegenüber dem Irrationalen oder sich der alles beherrschenden Vernunft nicht einfach Unterwerf-

22 Vgl. zu dieser die verschiedenen Phasen des Abendlandes durchlaufenden Metaphorik und Metaphorologie Blumenberg, Hans: Die Lesbarkeit der Natur. Frankfurt am Main: Suhrkamp 1986.

23 Vgl. zum Begriff der Landschaft der Theorie Ette, Ottmar: Viellogische Philologie. Die Literaturen der Welt und das Beispiel einer transarealen peruanischen Literatur. Berlin: Verlag Walter Frey - edition tranvía 2013, S. 36-46; sowie (ders.): Roland Barthes. Landschaften der Theorie. Konstanz: Konstanz University Press 2013. 
enden enthalten, wie dies später die Vertreterinnen und Vertreter der Romantik prägten. Vor allem aber kennzeichnet ihn das immer wieder bohrende Bemühen um die Frage, wie das Glück auf dieser Erde vom Menschen erreicht werden kann; eine Frage, wie sie sich zu Beginn der neunten und damit vorletzten „Promenade“ dieses zu Lebzeiten nicht mehr fertiggestellten Buches mit aller Dringlichkeit stellt:

Das Glück ist ein permanenter Zustand, der hienieden für den Menschen nicht gemacht zu sein scheint. Alles befindet sich auf Erden in einem kontinuierlichen Flusse, welcher keinem Gegenstande erlaubt, eine konstante Form einzunehmen. Alles verändert sich um uns her. Wir verändern uns selbst, und nichts kann sich versichern, dass es morgen noch lieben wird, was es heute liebt. So sind alle Projekte des Glückes für dieses Leben letztlich Chimären. $^{24}$

Das zentrale Element dieses Spaziergangs, also eines Denkens in Bewegung und aus der Bewegung, ist der kontinuierliche Wandel, die ständige Veränderung, die permanente Umformung alles Seienden und nur scheinbar fest Gefügten. Auf den ersten Blick scheint diese Passage von der Wortwahl an das berühmte „Alles fließt“, an das „panta rhei“ des griechischen Philosophen Heraklit anzuknüpfen, der zu seiner Zeit bereits bekanntlich feststellte, dass sich auf der Erde alle Dinge in stetigem Wandel befänden. Bei näherer Betrachtung aber wird diese Idee, dass alles im Flusse sei, mit der Sehnsucht des Menschen nach Glück und mit der Problematik verbunden, dass nichts garantieren könne, dass wir auch morgen noch lieben werden, was wir heute so stark mit unserer Liebe umfangen.

Aus dieser beweglichen, gleichsam im Vorübergehen erstellten Konfiguration entsteht ein tragisches Lebensgefühl, ein - um mit dem spanischen Philosophen Miguel de Unamuno zu sprechen - Sentimiento trágico de la vida, das eindeutig aus der Perspektivik des modernen Subjekts heraus wahrgenommen wird. So befindet sich selbst das antike „panta rhei“ im Wandel, wird es in dieser Passage bei Rousseau doch auf eine Frage moderner Subjektivität projiziert, die das Subjekt selbst und sein Lebensgefühl in stetigem Wandel weiß. Nichts ist sicher, nichts ist gewiss: Alle Dinge verändern sich so, dass sie vom Menschen niemals fest-gestellt werden können. Sicher ist folglich nur, dass nichts unwandelbar und sicher ist. Und daher könne es auch kein permanentes Glück des Menschen auf Erden geben.

Was aber, wenn sich selbst das, was den Schriftsteller auszeichnet, wenn sich die Grundlage all seines Schreibens, all seinen Formulierens selbst verändern würde? Was also, wenn ihm seine Sprache selbst entglitte, wenn sie sich also nicht mehr seinem Willen unterwerfen würde? Rousseau geht nur wenige Seiten später in seinem neunten Spaziergang dieser Frage nach:

24 Rousseau, Jean-Jacques: Les Rêveries du promeneur solitaire, S. 497. 
$\mathrm{Zu}$ keinem Zeitpunkt besaß ich je eine Geistesgegenwart oder die Fähigkeit, gut zu sprechen; aber seit meinen Unglücksfällen sind meine Sprache und mein Kopf immer stärker gestört. Ebenso entgleiten mir die Idee und das richtige Wort, und nichts fordert von mir eine klarere Unterscheidung und eine zutreffendere Wahl von Ausdrücken als jene Sätze, die man an Kinder richtet. Dies vergrößert in mir noch die Störung, nicht zuletzt auch die Achtsamkeit der Zuhörenden, die Deutungen und das Gewicht, das sie allem beimessen, was von einem Manne kommt, der ausdrücklich für die Kinder geschrieben hat und von dem man annimmt, dass er ständig in Orakeln zu ihnen spricht. Diese extreme Scheu und die Unfähigkeit, die ich in mir fühle, verstören mich, bringen mich aus dem Konzept, und ich fühle mich weitaus wohler vor einem Monarchen aus Asien als vor einem Kindchen, das es zum Plappern zu bringen gilt. ${ }^{25}$

Diese Passage führt uns eindrucksvoll vor Augen, welche Art von Geständnissen, von Bekenntnissen nun in diesen Träumereien eines spazieren gehenden Subjekts erscheinen. Es geht nicht um irgendwelche Ereignisse, Vorkommnisse, Gegebenheiten, sondern um innere Befindlichkeiten, Schwächen und Unsicherheiten, die das Ich reflektiert und seinem Lesepublikum zu Gehör bringt. Von keinen berühmten Persönlichkeiten, von keinen noch unentdeckten Genies ist die Rede, sondern allein von einem Ich, das über seine inneren Reaktionen auf allägliche Situationen nachdenkt. Das Ich berichtet und erzählt von Dingen, die nicht nur im 18. Jahrhundert zum Intimsten gehörten, die man niemandem anvertrauen mochte, und die doch in Les Rêveries du promeneur solitaire einen Kern jener Überlegungen betreffen, die das zeigende und über sich reflektierende Ich seiner Zuhörerschaft, seinem Lesepublikum offenlegen will.

Rousseau thematisiert zunächst ausgehend von der für das Ich im Zeitalter der Aufklärung nicht unbedingt schmeichelhaften Feststellung, dass es - wie schon in Les Confessions berichtet - über keine Geistesgegenwart verfüge und daher am beliebtesten Gesellschaftsspiel des französischen 18. Jahrhunderts, also an der Konversation in den Salons des Adels, nur wenig Anteil nehmen könne. Der Genfer Bürger hatte sich mit dieser seiner Unfähigkeit, mündlich zu brillieren, längst abgefunden. Doch dann gehen die Bekenntnisse weiter, spricht dieses Ich doch in der Folge von Störungen (,embarras“), die sich ausgelöst von all jenen Verfolgungen, deren Gegenstand das Ich geworden ist, in ihm gebildet haben und die ebenso seine Zunge und Sprechfähigkeit wie sein Denken, seinen Kopf beträfen. Dies ist schon eine weitergehende Aussage, welche nur noch wenige Zeitgenossen zu Protokoll gegeben hätten. Kein Wort wird hier darüber verloren, dass es sich um eine Alterserscheinung handeln könnte: Vielmehr sieht das Ich in seinen „malheurs“, in seinen Unglücksfällen die Aus-

25 Ebda., S. 501. 
löser jener Störungen, die es belasten und beeinträchtigen. Das Ich spricht von Sprachstörungen, deren es nicht Herr werden kann.

Doch anders als noch in Les Confessions werden nicht die Schwierigkeiten erwähnt, die das Ich empfindet, wenn es vor einem im Salon versammelten größtenteils adeligen Publikum, vor einer gesellschaftlichen Elite, möglichst frei und ungezwungen sprechen und sich gefällig ausdrücken soll. Es werden gerade die Sprach- und Sprechstörungen thematisiert, die vor einem Publikum auftreten, welches auf den ersten Blick als das einfachste überhaupt angesehen werden dürfte: eine Schar von Kindern, die sich um das Ich versammeln. Doch diese Kinderschar stellt ein besonders schwieriges und anspruchsvolles Publikum für einen Rousseau dar, der sich in seinem Emile wie auch in anderen Schriften direkt oder indirekt an dieses Publikum gewandt hatte und das nun von diesem weltberühmten Schriftsteller große und entscheidende Worte zu vernehmen hofft - zumindest will es dem Ich, das von erwarteten „Orakeln“ spricht, so scheinen. Und genau in diesem Augenblick fehlen dem ihm - und wir können seine Verstörung verstehen - die richtigen Worte. Dies kann man gerade bei einer mündlich und frei vorgetragenen Vorlesung sehr gut begreifen.

Ein Schriftsteller mit Sprachstörungen? Versuchen wir, aus einer anderen Perspektive auf den berühmten Autor Jean-Jacques Rousseau zu blicken und dies in einer Weise zu tun, wie dies die Zeitgenossen wohl überwiegend taten. Unter diesen freilich gab es viele, die Rousseau anfeindeten und sogar lauthals verspotteten. Wir werden auf diesen Punkt gleich noch einmal zurückkommen. Jedenfalls halte ich vor diesem Hintergrund meine Bezeichnung von Jean-Jacques Rousseau als dem ersten der unglücklichen Schriftsteller aufrecht. $\mathrm{Zu}$ präzise hat er in seinen autobiographischen Schriften - und in Les Rêveries du promeneur solitaire bis zu seinem Tode - eben diesen Sachverhalt immer wieder intensiv reflektiert.

Doch Jean-Jacques ist auch durch seine Betonung der Liebe, durch die Entfaltung einer wegweisenden Liebeskonzeption und durch einen Briefroman berühmt geworden, der im 18. Jahrhundert und weit darüber hinaus in beiden Welten äußerst erfolgreich war. Vielleicht wäre als Einstieg in unsere Auseinandersetzung mit der Liebeskonzeption Rousseaus am besten eine kurze Passage aus dem fünften Band von Giacomo Casanovas Histoire de ma vie geeignet, die ein knappes Portrait des Genfers zeichnet; denn über die Liebe wie auch über die Philosophie vermochte der Venezianer, mit dem wir uns noch eingehender auseinandersetzen wollen, Treffliches zu schreiben. Es handelt sich zugleich um eine Passage, die ein helles Licht auf die gegen Rousseau gerichtete Stimmung in weiten Teilen zumindest der ,Salongesellschaft' Frankreichs wirft. Nur konnte Casanova auf keinen Fall auf der Seite des Genfer Bürgers stehen, war er doch dem Rationalismus der Aufklärung viel zu nahe: 
Um diese Zeit gelüstete es Madame d’Urfé, die Bekanntschaft von J.-J. Rousseau zu machen, und so fuhren wir nach Montmorency, um ihn zu besuchen; wir brachten ihm Musiknoten zum Abschreiben, was er ganz hervorragend verstand. Man bezahlte ihm doppelt soviel wie einem anderen, aber er verbürgte sich auch dafür, dass man keine Fehler darin finden würde. Er lebte davon.

Wir fanden in ihm einen Menschen, der richtig urteilte und sich einfach und bescheiden gab, der aber weder durch seine Person noch durch seinen Geist hervorragte. Wir fanden aber nicht, was man einen liebenswürdigen Menschen nennt. Er schien uns ein wenig unhöflich, und mehr bedurfte es nicht, damit Madame d'Urfé ihn als Grobian betrachtete. [...] Auf der Rückfahrt nach Paris lachten wir über die Absonderlichkeit dieses Philosophen. Hier ein genauer Bericht über den Besuch, den der Prinz von Conti, der Vater des damaligen Grafen de la Marche, ihm abgestattet hatte.

Dieser liebenswürdige Prinz fuhr ganz allein nach Montmorency, nur um einen angenehmen Tag im Gespräch mit dem Philosophen zu verbringen, der bereits berühmt war. Er traf ihn im Park, sprach ihn an und sagte, er sei gekommen, mit ihm zu speisen und den Tag über ungezwungen mit ihm zu plaudern.

„Eure Durchlaucht werden eine recht kärgliche Tafel vorfinden; ich sage schnell Bescheid, dass man noch ein Gedeck auflegen soll.“

Er ging, kam zurück und führte den Prinzen, nachdem er zwei oder drei Stunden mit ihm spazieren gegangen war, in das Wohnzimmer, in dem sie speisen sollten. Als der Prinz drei Gedecke auf dem Tisch sah, fragte er:

„Wer ist denn der Dritte, mit dem Sie mich speisen lassen wollen? Ich glaubte, wir würden nur zu zweit bei Tisch sitzen.“

„Dieser Dritte, Monseigneur, ist mein anderes Ich. Es ist ein Wesen, das nicht meine Frau, nicht meine Geliebte, nicht meine Bedienerin, nicht meine Mutter und nicht meine Tochter ist, und doch alles zusammen.“

„Mag sein, lieber Freund; aber da ich nur hierher gekommen bin, um mit Ihnen zu speisen, will ich Sie lieber mit ihrem Universalwesen allein essen lassen. Leben Sie wohl.“

Solche Dummheiten begehen Philosophen, wenn sie aus Großmannssucht den Sonderling spielen. Die Frau war Mademoiselle Levasseur, der er, bis auf einen Buchstaben getreu, die Ehre seines Namens in Form eines Anagramms hatte zuteil werden lassen. ${ }^{26}$

Anhand dieser Passage erkennt man recht hübsch, welche gesellschaftliche Rolle Philosophen in der feudalistischen Gesellschaft des 18. Jahrhunderts für die Adeligen spielen. Sie sind oftmals kaum mehr als Kuriositäten, die man auch in einem gleichnamigen Kabinett hätte besichtigen können. Denn rasch wird in dieser sehr selbstverständlich daherkommenden Darstellung deutlich, wie sehr ein Philosoph wie Jean-Jacques Rousseau als Kuriosität und seltsames Tierchen, das man jederzeit im Zoo besuchen kann, herhalten muss und zugleich auch diese Rolle zu spielen gelernt hat. Casanova steht hier ganz auf der Seite der gesell-

26 Casanova, Giacomo: Geschichte meines Lebens. Frankfurt a. M.: Ullstein 1985, Bd. V, S. 253-255. 
schaftlichen Normen seiner Zeit, wusste er selbst sich doch an diese sozialen Umgangsformen hervorragend anzupassen - nicht aber Rousseau!

Schon zu Beginn des Zitats wird auch klar, wie man in der vorherrschenden Elite des 18. Jahrhunderts Menschen behandelte, die nicht über eine hohe Geistesgegenwart, über schnelle, witzige Einfälle, über in Sekundenbruchteilen entstehende tiefgründige philosophische Gesprächsthemen und über jene Reaktionsschnelligkeit verfügen, die man in Frankreich im Zeitalter der Aufklärung von den maßgeblichen „philosophes“ und Geistern der Zeit verlangte. Wer da nicht gleich positiv auffällt, dem wird rasch mangelnder Geist zum Vorwurf gemacht.

Nicht uninteressant ist aber auch, wie Rousseau seinerseits seine Lebenspartnerin einführt und ihr in der Tat letztlich die Züge eines weiblichen Universalwesens zuschreibt, das Mutter und Tochter, Geliebte und Ehegattin in sich vereinigt. So wird ein Frauenbild projiziert, das gleichsam die unterschiedlichsten Schichten der Geschlechterdifferenz aus männlicher Sicht fürwahr inkarniert. Die so bezeichnete Thérèse Levasseur erscheint zugleich in all diesen Rollen, die für den Genfer Philosophen durchaus lebenswichtig waren: Denn sie war es, die sozusagen - etwas salopp gesagt - Rousseaus Laden schmiss.

Zweifellos hatte Rousseau in dieser von Casanova kolportierten Anekdote versucht, gegenüber dem sich selbst einladenden Adeligen ein besonders geistreicher Gesprächspartner zu sein. Doch dieser Schuss ging nach hinten los. Die als Bonmot gedachte Äußerung des Philosophen mag vielleicht ein erster Vorgeschmack auf Rousseaus Liebeskonzeption sein, spielen doch die spezifischen Rollen der Frauen bei ihm eine grundlegende Rolle. Doch aus der Erzählung von Giacomo Casanova dürfte zugleich herauszulesen gewesen sein, wie sehr Rousseaus Kollisionen mit der adeligen Pariser Gesellschaft ihm das Bild eines gesellschaftsfremden Einzelgängers aufprägten, das ihn weit über seinen Tod hinaus begleitete. Es ist Rousseaus zeitlebens geführter Kampf gegen eine gesellschaftliche Anpassung, welcher seiner Sozialtheorie und seiner Gegenüberstellung von Gesellschaft und Gemeinschaft sehr überzeugend entsprach und zugleich an den Grundfesten eines feudalistisch verfassten Gemeinwesens rüttelte.

Persönliches Glück spricht freilich weder aus dieser hier nur kurz skizzierten Anlage wie aus den verschiedenen Epochen von Rousseaus Leben selbst. Weder Les Confessions noch die Rêveries du promeneur solitaire sprechen einem Glücksgefühl das Wort, das wir mit dem Namenszug Rousseaus verbinden könnten. Nicht das ersehnte Glück, in einer von ihm konzipierten Gemeinschaft zu leben, war dem Genfer Bürger und Uhrmachersohn beschieden, wohl aber die Intensität einer Reflexion und Selbstreflexion, die sein Leben zweifellos reicher machte. Dabei holte ihn immer wieder nicht nur seine kritische Haltung gegenüber einer Gesellschaft im Stile des Ancien Régime ein, son- 
dern seine kulturpessimistische Sichtweise der gesamten gesellschaftlichzivilisatorischen Entwicklung des Abendlandes überhaupt. Mit Rousseau stellt das moderne Subjekt die Grundlagen eines zivilisatorischen Prozesses, der die Entfaltung einer modernen Subjektivität überhaupt erst möglich machte, grundlegend in Frage. Dies ist eine in sich selbst widersprüchliche, paradoxe Konfiguration, in der das Erleben persönlichen Glücks und die Erfüllung gemeinschaftlicher Vorstellungen kaum als realisierbar erscheinen.

Und doch hat Jean-Jacques Rousseau immer wieder Bilder eines zeitweiligen persönlichen Glücks entworfen - eines Glücks freilich, das niemals permanenter Natur sein darf. Es sind Bilder eines bisweilen ekstatischen, aber dann bald schon abbrechenden Gefühls. Das Moment des Unglücks ist mit dem Moment der Trennung verbunden und diese Trennung ist durchaus unterschiedlicher Natur. In diesem Sinne einer selbstkritischen, autoreflexiven Subjektkonstituierung ist Rousseau nicht nur moderner - wenn Sie so wollen - als Voltaire; er repräsentiert auch die Moderne in einem anderen, zerrisseneren Sinne als jener letzte der glücklichen Schriftsteller. Letzterer avancierte gleichwohl für Jean-Paul Sartre nicht zu Unrecht zu einer der prägenden Gestalten für ein anderes Element der Moderne, für das Engagement innerhalb der bürgerlichen Gesellschaft. Die Kinder der Aufklärung sind, wie die der Revolution, sehr zahlreich und brachten eine Nachkommenschaft hervor, die bis in unsere Zeit reicht. Geht diese Epoche in den Wirren eines um sich greifenden Populismus, mit absichtsvollen Wirrköpfen wie Donald Trump, Boris Johnson oder Jair Messias Bolsonaro zu Ende? Wir wollen nicht hoffen, dass Flauberts geschichtspessimistische „éternelle bêtise de tout“ und die Verdummung ganzer Gesellschaften über Selbstreflexion und kritische wissenschaftliche Überprüfung obsiegen. Nicht nur die Aufklärung, sondern auch die Bedrohung der Aufklärung ist transatlantisch!

An dieser Stelle aber sollten wir uns nun definitiv einer für die Liebeskonzepte Rousseaus, aber auch des nachfolgenden Jahrhunderts zentralen Narration annähern, der bis heute wie kein anderer Text Rousseaus die nach eigener Diktion ,romanesken` Züge des Genfer Schriftstellers repräsentiert: dem Briefroman Julie ou la Nouvelle Héloïse. Im Titel dieses äußerst erfolgreichen Romans, der zusammen mit Voltaires Candide und Guillaume-Thomas Raynals Histoire des deux Indes den größten Bucherfolg des französischen 18. Jahrhunderts darstellte - im Rahmen unserer Vorlesung beschäftigen wir uns mit allen drei Texten -, findet sich bereits der Hinweis auf eine Liebespassion. Es handelt sich um eine Liebesleidenschaft, die eine tiefe Spur aus dem Mittelalter bis in die Gegenwart hinterlassen hat. Sehen wir uns diese Spur der Passion von Abélard und Héloïse in aller notwendigen Kürze einmal näher an!

Abélard oder Abaelardus war ein scholastischer Theologe und Philosoph, der im Jahre 1079 in Palet bei Nantes das Licht der Welt erblickte und am 
21. April 1142 im Kloster St. Marcel bei Châlon verstarb. Den Zeitgenossen Rousseaus war seine Gestalt durchaus vertraut. Weltberühmt wurde er freilich weniger durch seine wichtigen philosophischen Schriften und Einsichten, als vielmehr durch seinen unglücklichen Liebes- und Ehebund mit der schönen Heloïse, der Nichte des Kanonikus Fulbert in Paris, der ihn aus Rache für diese unerlaubte Liebesbeziehung letztlich entmannen oder kastrieren ließ. Sie merken schon: Auch diese Geschichte geht nicht gut aus ...

Gegenüber seiner großen Liebesgeschichte mit Héloïse tritt Abaelardus' Rolle als Mitbegründer und Hauptvertreter der scholastischen Methode etwas in den Hintergrund. In Philosophie wie Theologie hinterließ er jedoch sichtbare Spuren: Im Universalien-Streit milderte er den extremen Nominalismus seines Lehrers Roscelinus zum Konzeptualismus, in der Theologie suchte er Glauben und Wissen zu versöhnen. In seiner Ethik wiederum vertrat er den Standpunkt, dass es nicht auf die Schriften und Werke, sondern vor allem auf die Gesinnung ankomme. Doch wir wollen uns nicht mit dem Scholastiker beschäftigen, sondern mit dessen unsterblicher Liebe.

Im Kern dieser Liebesgeschichte steht die Tatsache, dass der bereits berühmte Abélard die im Rufe hoher Gelehrsamkeit stehende Héloïse - sie lebte von 1100 bis 1163 - verführte. Es war ihr Onkel, der Kanonikus selbst gewesen, der den erfahrenen Abélard zu ihrem Lehrer bestellt hatte. Nach ihrer Liebesvereinigung entführte sie Abélard zu seiner Schwester in die weit entfernte Bretagne, wo sie einen Jungen als Frucht der gemeinsamen Liebe zur Welt brachte. Verschiedene Versionen sprechen von einer geheimen Eheschließung; doch ging Héloïse, um allen Gerüchten ein Ende zu bereiten, in das Kloster von Argenteuil. Ihr Onkel glaubte freilich an Betrug, ließ Abélard überfallen und kurzerhand kastrieren. Während Héloïse ganze sieben Jahre in ihrem Kloster zubrachte, brachte sich Abélard zunächst im Koster Saint-Denis in Sicherheit, wandte sich aber dann einem Zufluchtsort in der Nähe von Troyes zu, von wo aus er wieder $\mathrm{zu}$ lehren begann und wiederum Schüler um sich versammelte. Im Jahre 1131 übergab Abélard seinen Zufluchtsort an Héloïse und deren aus Argenteuil geflohenen Mitschwestern, musste sich angesichts übler Nachrede aber bald wieder von seiner Geliebten trennen. Doch so wechselvoll und tragisch diese Liebesgeschichte auch verlief: Um in die Überlieferung und damit in die Ewigkeit einzugehen, musste noch die Schrift hinzutreten - und so geschah es!

Héloïses und Abélards berühmter Briefwechsel soll durch seine autobiographische Schrift Historia calamitatum mearum ausgelöst worden sein, in welchem die junge Frau ihre andauernde Liebe beschwor, ihr Liebespartner sie aber auf die Liebe zu Gott verwies. Abélard, dem der Papst verziehen hatte, starb letztlich in dem einsamen Kloster von Saint-Marcel. Héloïse gelang es, seine Umbettung in ihr Kloster, seine alte Wirkungsstätte, zu erreichen, wo sie 
später Äbtissin war und schließlich an seiner Seite beerdigt wurde. Seit 1817 ruhen beider Gebeine auf dem Friedhof Père-Lachaise zu Paris und fanden damit am Begräbnisort der Illustren ihre wohlverdiente Vereinigung.

Das Schicksal dieses unglückseligen mittelalterlichen Liebespaares wurde von einer Vielzahl von Schriftstellern bearbeitet und entwickelte sich zu einem wichtigen Stoff der europäischen Liebesliteratur. Die Briefe der beiden gerieten nach ihrer Veröffentlichung im 17. Jahrhundert zum Ausgangspunkt für literarische Bearbeitungen vielfältigster Art. Im 18. Jahrhundert kam es vor allem ausgehend von England aus zu einer intensiven Auseinandersetzung mit diesem Stoff, in dessen Zentrum immer wieder diese Liebesbriefe zweier Schmachtender stehen. An diese auch in Frankreich weitergesponnene Traditionslinie des Stoffes konnte Rousseau 1761 mit seinem großen Briefroman über zwei Liebende am Fuße der Alpen anknüpfen. Dabei diente ihm gerade die häufige Fokussierung auf die junge Frau als Leitlinie seiner freien Bearbeitung; eine Fokussierung, die bereits in der Titelwahl seines Romans signalisiert wird.

Der in seinem Briefroman zum Ausdruck kommende Konflikt zwischen subjektiver Empfindung und gesellschaftlicher ,Vernunft' (im Sinne von Normen und Moralvorstellungen) entspricht ganz der gegen die einseitige Vernunftausrichtung weiter Teile der französischen Aufklärungsphilosophie gerichteten Position Rousseaus. Die fiktionale Literatur gab seinem philosophischen Denken ein gegenüber der Philosophie weiteres Erprobungs- und Spielfeld. Der Genfer Philosoph situiert diesen Konflikt innerhalb einer radikalen Gesellschaftskritik, innerhalb derer er unterschiedliche Gesellschaftsmodelle im Roman fiktional gegeneinander aufbietet. Dies ist die erprobende und vielleicht mehr noch spielerische Dimension in Rousseaus Briefroman.

Denn es sind die simplen sozialen Schranken einer überkommenen Ständeordnung des Ancien Régime, welche eine eheliche Verbindung zwischen Julie d'Etanges und ihrem bürgerlichen Hauslehrer Saint-Preux untersagen und definitiv verunmöglichen. Wie bei Héloïse und Abélard geht es also um eine große Liebe, die nicht sein darf und schmerzhaft an gesellschaftliche Schranken stößt.

Die junge Frau muss sich entscheiden. Julies Entschluss, den älteren Herrn de Wolmar zu ehelichen, um im Schutze des Ehesakraments ihrem eigentlichen Geliebten treu bleiben zu können, trägt der in Julie unsterblich verliebte SaintPreux unter Qualen mit. Von Mylord Edouard überzeugt, geht der noch immer liebestrunkene Hauslehrer auf eine für die Epoche charakteristische Weltumsegelung, von welcher er erst nach Jahren wieder an den Genfer See zurückkehrt. Jean-Jacques Rousseau besaß ein geradezu seismographisches Gespür für seine Zeit und hatte verstanden, dass sich die Horizonte in der zweiten Hälfte des 18. Jahrhunderts grundlegend geweitet hatten: Es war die Zeit einer sich be- 
schleunigenden zweiten Phase der Globalisierung, die Saint-Preux auf einer englischen Fregatte hautnah miterleben darf.

Doch diese Abwesenheit hat romanintern nur aufschiebenden Charakter. Das tragische Ende einer sich selbst gegenüber stets treuen Julie, die im Roman zunehmend zu einer Heiligen stilisiert wird, erlebt der gereifte, aber noch immer im Überschwang seiner Gefühle lebende Saint-Preux tragisch mit. Diese Tragik entspricht durchaus jener Analyse, wie sie Denis de Rougemont über die Liebe im Abendland, dem wir ein Kapitel unserer Vorlesung über LiebeLesen ${ }^{27}$ gewidmet haben, vorangetrieben hat. Nur über die glückende und glückliche Liebe gibt es nichts zu sagen.

Die Liebe von Héloïse und Abélard im 18. Jahrhundert aber ist höchst wortreich und füllt einen umfangreichen Briefroman. Die stark von den Landschaften am Genfer See und in den nahegelegenen Alpen angeregten und durch die Naturempfindungen stimulierten Liebesbriefe zwischen Saint-Preux und seiner Julie machen nahezu die erste Hälfte dieses weite Leserkreise ansprechenden Briefromans aus. Immer mehr weitet sich die Zahl der Briefeschreiber und -empfänger aus und macht einer Reflexion gesellschaftlicher Utopien Platz, in welchen der ideale Gesellschaftszustand mehr herbeigesehnt und herbeigeschrieben als beschrieben und analysiert wird. Doch dient auch in diesem $\mathrm{Zu}$ sammenhang der Roman dem Philosophen als ein Erprobungsraum, der seine Ideen und Vorstellungen einem breiten Lesepublikum zugänglich macht.

Die von Rousseau gewählten Landschaften verwandeln sich in Landschaften der Theorie: nicht nur in den Alpen, wo die Transparenz des Blickes zu einem wichtigen Gut wird, sondern auch in den welligen und fruchtbaren Landschaften des Schweizer Voralpenlands und Alpenvorlands. Clarens steht im Roman für jenen Ort, an welchem Julie im Kreise ihrer Familie, ihres Mannes und ihrer beiden Kinder zu sich selbst gefunden zu haben scheint; an diesem schon namentlich von Klarheit durchfluteten locus amoenus situiert sich die eigentliche gesellschaftliche Utopie, mit welcher Rousseau seinen philosophischen Gesellschaftsroman ausstattet. Die beiden Liebenden jedoch können einander nicht vergessen und sind auf immer aneinander gebunden, so vernunftbezogen Julie und deren adeliger Ehemann auch immer argumentieren mögen. Die Liebe durchzieht alle Ebenen und Episoden des Romans selbst dort, wo von ihr nicht die Rede ist oder wo wir - wie etwa bei der Weltumsegelung SaintPreux' - Tausende von Meilen vom Ort des Geschehens entfernt sind.

So gehen die beiden Liebenden in die Geschichte des Romans ein als die neuen Héloïse und Abélard des 18. Jahrhunderts, die von den gesellschaftlichen

27 Vgl. Ette, Ottmar: LiebeLesen (2020), S. $135 \mathrm{ff}$. 
Normen ebenso um ihre Liebe betrogen wurden wie das unsterbliche französische Liebespaar aus dem Hochmittelalter. Nichts kann einer solchen Liebe widerstehen! Und doch ist Saint-Preux nicht mehr in Julie de Wolmar verliebt, sondern in jene junge und unbeschwerte Julie d'Etanges, die der junge Hauslehrer kennen und lieben gelernt hat. Ihr Zauber umgibt ihn ein Leben lang. Ist seine Liebe damit aber ruhig gestellt? Keineswegs! Denn es werden die gesetzten Grenzen zwar von den beiden Liebenden anerkannt und respektiert, aber ohne dass sich an der Tragik ihrer Liebesbeziehung dadurch etwas geändert hätte. Die Liebe wird durch den Verzicht im eigentlichen Sinne verklärt und gleichsam sublim(iert) sakralisiert. Es ist eine Liebesbeziehung in den Zeiten moderner Subjektivität, polyperspektivisch von allen Seiten kommentiert.

Clarens ist Rousseaus konkrete Utopie, der literarische Ort, an dem er seine Gesellschaftsvorstellungen liebevoll ausmalte. Es ist eine Gesellschaft und Gemeinschaft, an der alle gleichmäßige Anteile haben und partizipieren. In dieser Ausrichtung ist sie deutlich gegen alle Gesellschaftsmodelle des Ancien Régime gerichtet, auch wenn sie sich deutlich unter patriarchalischer Führung befindet. Gesellschaftliche Zivilisation und Natur sowie Naturempfinden sind miteinander versöhnt, wie dies etwa am Erntefest in Clarens programmatisch vorgeführt wird. Die patriarchalische Leitung prägt alles. Doch zugleich gibt es auch eine unbestrittene weibliche Autorität. Wie in einem französischen Salon des 18. Jahrhunderts ist alles um die schöne, aber zugleich pragmatische Julie im Kreis versammelt - es ist ein Gemeinschaftsmodell, das rund um den Mittelpunkt der Frau seine Erfüllung findet, während im Hintergrund die männliche Macht die Fäden in der Hand behält. Doch die schöne Héloïse regiert über alle und alles: Wie eine Salonière herrscht Julie über ihren Kreis.

In all dies hinein ist die erkaltete, aber immer noch allgegenwärtige Herzensschrift einer unabgegoltenen und letztlich tragischen Liebe geschrieben. Dieser Schrift, die sich nicht allein durch die Liebesbriefe, sondern durch alle Seiten des Briefromans zieht, kann niemand ausweichen - auch und gerade das Liebespaar nicht. Die Liebe ist allgegenwärtig und zugleich auf Erden nicht zu leben. Nach dem Unfall in der Seenlandschaft bereits im Sterben liegend, gesteht Julie in einem letzten Brief Saint-Preux ihre unveränderte und starke, aber zugleich schuldige und himmlische Liebe. Ihre Liebe wird himmlisch sein, weil sie auf Erden nicht zu verwirklichen ist.

Wie stark diese Liebeskonzeption, die allein in ihrem Verzicht lebbar wird, auf die nachfolgenden Schriftstellerinnen und Schriftsteller nicht nur Frankreichs gewirkt hat, lässt sich kaum ermessen. Die Empfindsamkeit des Rousseau'schen Paares prägte zum einen die Vorstellungswelt von Paul und Virginie in Bernardin de Saint-Pierres großem gleichnamigen Roman, befeuerte aber auch die Vorstellungswelt einer Emma Bovary, mit der sich Gustave Flaubert 
über die Liebeskonzeptionen der Vorromantik durchaus mokierte. Ebenso als Liebesroman wie auch als Gesellschaftsroman zeugte Julie ou la Nouvelle Héloise eine reiche Nachkommenschaft, selbst wenn die Gattung des Briefromans im weiteren literarhistorischen Verlauf ihre Ausstrahlungskraft verlor. Die „beiden Liebenden am Fuß der Alpen“, wie es paratextuell heißt, zogen viele Leserinnen und Leser mehrerer Generationen auf beiden Seiten des Atlantiks in ihren Bann.

Dieser Briefroman der Aufklärungszeit bot den Autor`innen wie ihren Lese$\mathrm{r}{ }^{\star}$ innen viele Vorteile. Jürgen von Stackelberg betonte wie viele andere die Verbindung zwischen dem Briefroman des 18. Jahrhunderts und der Subjektivität des Individuums, die sich im Brief ausdrückt, womit gleichsam eine bürgerliche Öffentlichkeit begonnen habe. ${ }^{28}$ Natürlich dürfen wir über aller Liebesrhetorik nicht vergessen, dass die Epoche des Briefromans auch mit der Epoche eines modernen Postwesens zusammenfällt. Selbstverständlich hatten schon Héloïse und Abélard sich gegenseitig Briefe geschrieben - aber eben nicht mit derselben Schnelligkeit, wie dies im 18. Jahrhundert der Fall war. Die spätere Abwertung des Briefromans in den beiden nachfolgenden Romanen führte auch zu einer Abwertung des Briefs und der Korrespondenz als literarischer Gattung; eine Tatsache, die lange Zeit der literarischen Einordnung der Briefe von Rahel Levin Varnhagen überaus schadete. Doch auf diesen Punkt kommen wir noch zu sprechen ...

Im 18. Jahrhundert ist dies noch anders: Der Brief wird im Kontext der Empfindsamkeit - so Jürgen von Stackelberg weiter - wie der Abdruck einer Seele gelesen. Zugleich wird der Briefroman um 1750 unverkennbar als sich herausbildende Gattung begriffen, welche literarisch eine Vielzahl von Vorteilen bot. Dabei kommen ihm Unmittelbarkeit des Ausdrucks, Anteilnahme des Lesepublikums an der Leidenschaft, Improvisationscharakter und Gefühlsausdruck wie bei keiner anderen Gattung zugute, wobei zugleich auch eine Nähe zum Konversationsstil (in den Salons) und zur Mündlichkeit besteht. Man könnte zudem auch von einer Ästhetik der „négligence“ sprechen, die in ihm zum Tragen kommt: scheinbar schnell hingeworfene Skizzen, spontan und unmittelbar entworfen und die intime Seele, die heimlichen Gefühle aufdeckend. Überdies zeigt sich auch die Nähe zum Theater, wobei im Briefroman auf Grund der Kommunikationssituation freilich die Dimension der Seelenanalyse stärker gegeben ist. Ganz im Sinne Rousseaus spricht hier das Herz zum Herzen auf direkte, unverschleierte und transparente Weise.

Nun haben wir ausreichend über den Liebesdiskurs bei Rousseau und seine Einbettung ins Jahrhundert der Aufklärung gesprochen, um uns nun dezi-

28 Vgl. Stackelberg, Jürgen von: Der Briefroman und seine Epoche. Briefroman und Empfindsamkeit. In: Romanistische Zeitschrift für Literaturgeschichte (Heidelberg) 1 (1977), S. 293-308. 
diert der Textanalyse und einem Close Reading der Liebe in Julie ou la Nouvelle Héloïse zuzuwenden. Diese genaue und detaillierte Textanalyse und Interpretation soll herausarbeiten, welche Besonderheiten die Liebeskonzeption Rousseaus in dieser Übergangszeit zwischen den Lumières, der Empfindsamkeit und der nachfolgenden Romantik aufweist. Steigen wir also ein in die Liebesbriefe zwischen unseren beiden Liebenden und sehen wir, was Julies berühmter Kuss bei ihrem schmachtenden jungen Hauslehrer anrichtet:

\footnotetext{
Was hast Du getan? Ah! Was hast Du getan, meine Julie? Du wolltest Dich bei mir bedanken, und $\mathrm{Du}$ hast mich verloren. Ich bin trunken oder bin vielmehr der Sinne bar. Meine Sinne sind verändert, all meine Fähigkeiten sind verwirrt durch diesen tödlichen Kuss. Du wolltest meine Übel besänftigen! Du Grausame!, Du hast sie noch bitterer gemacht. Gift ist es, was ich auf Deinen Lippen trank: Es fermentiert und verbrennt mein Blut, es tötet mich, und Dein Mitleid lässt mich sterben.

Oh, unsterbliche Erinnerung an diesen Augenblick der Illusion, des Deliriums und der Verzückung. Niemals, niemals wirst Du aus meiner Seele getilgt; und solange die Reize von Julie dort eingemeißelt stehen, solange dieses hin und her geschüttelte Herz mir Gefühle und Seufzer liefern wird, wirst Du die Folter und das Glück meines Lebens sein! ${ }^{29}$
}

Dies also kann ein simpler Kuss eines jungen Mädchens auf die Lippen ihres Hauslehrers bewirken. Lassen Sie uns nach diesem Schwelgen im vorromantischen Liebesdiskurs vorsichtshalber die Regeln dieses Diskurses durchbrechen und zu einer nüchternen Sprache literaturwissenschaftlicher Analyse finden! Denn man könnte zu dieser Passage im Grunde mehr oder minder trocken anmerken: Es geht eigentlich um drei Flüssigkeitskreisläufe. Erstens ist da die Flüssigkeit, die Saint-Preux von den Lippen Julies empfängt; zweitens die Flüssigkeit seines eigenen Blutkreislaufs; und drittens die Flüssigkeit der Tinte bei seinem eigenen Schreiben in jener Schrift, die fraglos die Schrift seines Herzens ist, das nicht umsonst im obigen Zitat ekstatisch angerufen wird.

Schauen wir uns diesen komplexen Kreislauf noch etwas genauer an! Die drei Kreisläufe von Flüssigkeiten durchdringen sich und träufeln das Gift in die Blutbahn, die Blutbahnen nähren das Herz und seine Emotionen, das Herz wiederum antwortet auf die Flüssigkeit jenes Giftes, das Saint-Preux auf den Lippen von Julie sammelte, mit einer absoluten Verwirrung aller Sinne. Wie, diese Verwirrung aller Sinne ist Ihnen sprachlich noch nicht nahe genug? Dann lassen Sie uns von einer „Total Eclipse“ sprechen, die alle Sinne und alles Einsehen verdunkelt! Das Gift ist in den germanischen Sprachen stets ein doppeltes Liquid: Es ist einerseits eine zerstörerische Flüssigkeit, die bisweilen hinterrücks und insgeheim ihre Wirkung tut, zum anderen ist es zugleich aber immer auch Gabe und Geschenk, wie wir das aus

29 Rousseau, Jean-Jacques: Julie ou la Nouvelle Héloïse, Paris: A. Houssiaux 1852-1853, S. 30. 
dem englischen „gift“ kennen. Ebenso ist die gesamte Szenerie des Kusses zwischen Julie und Saint-Preux ein „supplice“ und zugleich das „,bonheur“ des jungen Mannes: Der Kuss ist ein ambivalentes Pharmakon, das Verzückung und Verzweiflung zugleich in seine Seele träufelt.

In diesem kurzen Auszug aus dem vierzehnten Brief, den Saint-Preux an seine geliebte Julie d'Etange richtet, erfahren wir Grundlagen nicht nur der Liebeskonstellation und deren Fortschritte, sondern auch eine Vielzahl von (literarischen) Aspekten der Topik der Liebe im Kontext des Rousseau'schen Entwurfs und Schreibens. Aus dieser Passage wird deutlich, dass die Liebe des Hauslehrers zu seiner gelehrigen Schülerin Julie eine leidenschaftliche in dem Sinne ist, als sie in ihrer höchsten Ambivalenz stets auf dem Leiden beruht und mit aller Macht Leiden schafft. Insofern wird sie der zeitgenössischen Sichtweise der Liebesbeziehung zwischen Abélard und Héloïse durchaus gerecht.

Die Liebe beinhaltet das Glück und zugleich die Folter, wie Saint-Preux seiner Schülerin gesteht, die ihm als Lohn einen einzigen schüchternen Kuss gab. Dieser Kuss aber wird zum „baiser mortel“, zum tödlichen oder todbringenden Kuss, da der Liebende von den Lippen Julies zugleich die Liebe und das Gift, den Liebestrank und den Todestrank gekostet hat. Sofort ist in der abendländischen Liebeskonzeption - ganz im Sinne von Denis de Rougemont - die Liebe von Tristan und Isolde präsent und mit ihr eine Fülle transzendenter, religiöser Vorstellungen. All dies ist in der Ambivalenz des Pharmakons als Gabe und als Gift enthalten. Beides ist in dieser Körperflüssigkeit allgegenwärtig: Glück und Folter, Leben und Tod sind unausweichlich miteinander verbunden. Es wird für Julie wie für Saint-Preux fortan nicht mehr möglich sein, sich entweder für das eine oder das andere zu entscheiden: Beide sind auf immer miteinander liiert.

Die Konsequenzen dieses Kusses und dieser Liebe sind in ihrer Ambivalenz beiden Liebenden präsent. Liebe und Tod werden von der Szene des „baiser mortel“ an aufs Engste miteinander verbunden. Zugleich ist die Liebe in diesem ersten Teil des Romans einerseits unschuldig, in „naiveté“ und „franchise“ vorgetragen und gelebt; zum anderen aber ist diese Auffassung von Liebe sich auch der unüberwindlichen Standesgrenzen bewusst, welche es nicht erlauben, dass die adelige junge Dame einen Bürgerssohn niederer Herkunft heiratet. Denn die Möglichkeit eines kurzen Flirts - eines One-Night-Stand - ist in dieser Liebeskonzeption ohnehin nicht vorgesehen. Beide Liebende wissen von der realgesellschaftlichen Unmöglichkeit ihrer Liebesbeziehung und können ihr doch nicht ausweichen. Liebe ist stets etwas, das eine bestehende Gesellschaftsordnung herausfordert, unabhängig von der Art und Weise dieser Liebe - zumindest dann, wenn sie an geltende Normen und Verpflichtungen rührt und mit diesen kollidiert. Denn die Liebe ist nie unschuldig - erst recht nicht bei Rousseau! 
Die Konsequenzen für den Briefroman des Genfer Bürgersohnes sind unmissverständlich: Denn aus der genannten Konstellation ergibt sich die ganze Rhetorik von Geburtsadel, Geldadel und Seelenadel, welche diesen Briefroman durchzieht und nicht selten auch in einen geradezu sozialrevolutionären, die Standesgrenzen überschreitenden Diskurs einmündet. Die Trennlinie zwischen Bürgertum und Adel wird nach der Heirat Julies mit dem Adligen de Wolmar aufrechterhalten, zusätzlich aber mehr als alles andere durch die unbeweglichen Grenzen zwischen leidenschaftlicher Liebe und christlicher Ehe - und somit der christlichen institutionalisierten Liebe - verstärkt.

Die Passion, also gelebte Leiden und Leidenschaften, entzündet sich an dieser Konstellation einer Unwegbarkeit und Unwägbarkeit der Liebe, die doch immer wieder nach Formen ihres Ausdrucks und ihrer Selbstversicherung sucht. Die Entstehung von Liebesbeziehungen wirft stets ein präzises Licht auf die sie ermöglichenden oder verunmöglichenden Gesellschaftsbeziehungen. Für die Liebenden in der Fiktion ergibt sich freilich kein Ausweg, keine Ausflucht; für die Gesellschaft in der Sozialtheorie Rousseaus dagegen schon. Eben hier liegt der sozialrevolutionäre Akzent dieses so facettenreichen Briefromans: Der Bürgersohn schreibt gegen eine feudalistische Stände- und Liebesordnung an.

So wird die Liebe zum eigentlichen Katalysator für die Entfaltung der eigenen Subjektivität des Individuums und einer kollektiv verstärkten Subjektivität, wie sie für unsere Moderne charakteristisch geworden ist. In immer neuen Anläufen, in immer neuen Briefen versichern sich unsere Liebenden, aber auch andere Stimmen im Briefroman ihres individuellen, ihres einzigartigen Subjektcharakters. Die moderne Subjektivität wird - wieder und wieder gespiegelt in der Liebe - dadurch zum Herzstück innerhalb einer sich ständig modernisierenden Gesellschaft, wie sie gerade die von Julie und de Wolmar geschaffene Gesellschaftsutopie von Clarens am Genfer See darstellt. Dort zeigt Rousseau unweit seiner Geburtsstadt auf, wohin die Auflösung einer Ständegesellschaft tendieren müsste. Die Liebe weist dabei den Weg, wenn der utopische Grundzug auch zunehmend deutlicher hervortritt.

Der Liebestrank, von den Lippen Julies getrunken, und damit die körperliche Flüssigkeit führt zur Trunkenheit von Saint-Preux, zugleich aber auch zum Verlust aller sinnlichen und kognitiven Fähigkeiten des armen Hauslehrers, wirkt also in der Tat wie ein Gift, das den anderen zugleich lähmt und lahmlegt. Die junge unschuldige Frau, die diesen Trank verabreicht, bleibt dadurch zwar das geliebte Wesen, wird andererseits aber auch zur Grausamen, zur ,belle dame sans merci“, welcher Saint-Preux willenlos ausgeliefert ist. Denn sie ist es ja, die die Leidenschaft erregt, aber im Grunde nicht stillt, sondern nur immer von neuem entfacht, bis dass sein Blut entflammt und seine ganze Person in Flammen steht. Und dies alles, so werden Sie fragen, wegen eines unschuldigen Kusses? 
Ja, nur wegen eines Kusses! Das Mitleiden der höhergestellten Dame - und auch hier sehen wir noch die Bezüge zur höfischen Liebe und zur „belle dame sans merci“, nur mehr transportiert in den Kontext einer Gesellschaft auf dem Weg in ihre vom Bürgertum beherrschte Form - beendet das Leiden des Liebenden nicht. Vielmehr verstärkt es nur die tödliche Wirkung jener Flüssigkeit, die er von ihr entzückt empfangen hat. Zugleich ist all dies in seiner Sterblichkeit vor dem Hintergrund des drohenden Todes - doch immer prospektiv ins Ewige, ins Unvergängliche, in ein Stillstehen der Zeit gehoben. Denn der Augenblick der Liebe wird zum unvergänglichen Zeitraum, der in der Tat Saint-Preux niemals mehr vergehen wird, auch wenn ihn die Gesellschaft zwingt, diesen Augenblick einer für immer vergangenen Zeit zu überantworten. Doch vergessen kann er niemals mehr. Und - wie schon Nietzsche wusste - alle Lust will Ewigkeit ... ${ }^{30}$

Hierin besteht das „enchantement“, die Verzauberung und Verzückung durch die Liebe. Sie hält sich hinter den Reizen, hinter den „charmes“ der schönen Julie grausam verborgen. Zugleich gibt es eine Art Topographie des Menschen beziehungsweise des menschlichen Körpers, genauer: des Körper-Leibs des Liebenden, die sich deutlich abzeichnet. Dabei geht es weniger um eine Objektivierung bestimmter Körperteile, um ein bestimmtes Körper-Haben, als vielmehr um ein Leib-Sein und um das Fühlen gewisser Organe.

Denn so wie die „charmes“, das Kharma von Julie, in die Seele eingeschrieben sind - und die Schreibmetaphorik ist hier bedeutungsvoll -, so ist auch das Herz zu jenem Ort und Organ des Körpers des Liebenden geworden, das die Gefühle der Liebe hervorbringt, die unauslöschlich bleiben. Ungezählte Male wird immer wieder dieses Herz des Liebenden beschworen, das den Ort der Liebe darstellt, das zugleich aber auch jene Flüssigkeit - das Blut - zur Verfügung stellt und in Umlauf setzt, das die erkaltete Herzensschrift der Romantiker erzeugt. Der Blutkreislauf ist nicht nur ein Phänomen der Natur, sondern auch eines von Kultur und Literatur.

Man könnte in diesem Zusammenhang von einer körper-leiblichen Dreiecksbeziehung sprechen. Im Dreieck von Kopf, Herz und (schreibender) Hand nimmt das liebende Herz die beherrschende Position ein. Es wird in der Schrift gespiegelt und erreicht den Liebespartner über das Lesen, über die Lektüre, welche direkt ins Herz gehen: So stellt sich über das Lesen der Schrift des Liebespartners eine Kommunikation direkt von Herz zu Herz ein - und nicht mehr, wie die Rationalität der Aufklärung noch vermuten ließe, von Hirn zu Hirn.

30 Vgl. Nietzsche, Friedrich: Das andere Tanzlied. In (ders.): Werke in vier Bänden, Bd. 4, S. 286. 
Als versierter Schriftsteller vermag Rousseau auf der intertextuellen Klaviatur virtuos zu spielen. Das Modell der unglücklichen Liebe von Héloïse und Abélard ist in Rousseaus Text implizit, nicht selten aber auch explizit als Bezugsgröße ständig präsent. Im vierundzwanzigsten Brief etwa schreibt der gebildete Hauslehrer Saint-Preux an seine Julie von jenen Warnungen, die er ihr mit Blick auf die Briefe zwischen den beiden Liebenden einst mitgegeben hatte:

Als die Briefe von Héloïse und Abélard Ihnen in die Hände fielen, so wissen Sie, was ich
Ihnen von dieser Lektüre und vom Verhalten dieses Theologen sagte. Stets habe ich Héloïse
beklagt; sie besaß ein Herz, das für die Liebe gemacht war, doch Abélard erschien mir
immer als ein Elender, der seines Schicksals würdig war und ebenso wenig die Liebe wie
die Tugend kannte. Nachdem ich ihn verurteilt, ist es da notwendig, dass ich ihn nun nach-
ahme? Unglück für einen jeden, der eine Moral predigt, welche er selbst nicht praktiziert! ${ }^{31}$

Am Ende des 17. und zu Beginn des 18. Jahrhunderts hatte eine wahre Schwemme von Ausgaben und Veröffentlichungen zum Briefwechsel zwischen Héloïse und Abélard eingesetzt, so dass schon die Encyclopédie in ihrem Artikel zur Scholastik fragen musste, ob es denn noch jemanden gebe, der nicht diese berühmten Liebenden kenne. Rousseau schrieb also bewusst im Geist seiner Zeit und beflügelt von den Vorstellungen, die man auf das mittelalterliche Liebespaar projizierte. Denn die unglückliche Liebe zwischen den beiden christlichen Liebenden war längst sprichwörtlich geworden. Zugleich waren die gesellschaftlichen, theologischen und kirchlichen Zusammenhänge einem Mittelalter verpflichtet, das man aus der Perspektive des Aufklärungszeitalters eher als finstere Periode ansah.

Jean-Jacques Rousseau machte in seinem Briefroman - wie wir aus obigem Zitat ersehen können - explizit auf den Bezug zum mittelalterlichen Liebespaar aufmerksam und baute die Briefe in die Diegese geschickt und zugleich mit einer Deutung beider Figuren durch den liebenden Hauslehrer ein. Im Mittelpunkt von Saint-Preux' Lektüre der Liebesbriefe steht Julie, die Abélard bei weitem an Liebesfähigkeit und Gefühlen überlegen sei. Und diese Einschätzung prägt auch den Briefroman des Genfer Autors, der den Hauslehrer zum Schüler seiner Julie macht.

Dies bedeutet, dass die mittelalterliche Héloïse für die neue, die moderne Héloïse, unsere Julie d'Etange nämlich, längst zum Vorbild und Modell geworden ist; trotz aller Warnungen von Saint-Preux, der im Übrigen seinerseits nur feststellen kann, dass er nicht sicher sei, die hohen moralischen Standards zu erfüllen, die er selbst an den Theologen Abélard angelegt habe. Immerhin sah er Gründe für das Schicksal Abélards, rechtfertigte also letztlich die Kastration. Und es wäre ein Leich-

31 Rousseau, Jean-Jacques: Julie ou la Nouvelle Héloïse, S. 41. 
tes, daraus auch immer wieder die von den Vaterfiguren wie de Wolmar ausgehenden Kastrationsängste unseres jungen Hauslehrers im Briefroman nachzuweisen.

Da hat es auch nichts $\mathrm{zu}$ bedeuten, dass die schöne Julie gegen Ende des Briefromans den Tod findet und Saint-Preux seine Geliebte beweinen muss. In der gesamten nachfolgenden Romantik werden die schönen Frauen sterben, und nichts geht im romantischen Roman, wenn es nicht über ihre Leiche, über die Leiche der schönen Frau geschieht. ${ }^{32}$ Saint-Preux steht zweifellos ständig im Schatten ihrer überlegenen Intelligenz und ihrer ausbalancierten, ausgeglicheneren Gefühlslandschaft. Das ermöglicht es freilich seinem Autor, ihn vielleicht stärker noch als Julie als Typus des modernen Subjekts zu zeichnen und in all seinen Verlegenheiten und Unsicherheiten zu portraitieren. Saint-Preux ist zweifellos die schwächere Figur; und eben deshalb dazu geeignet, dass Rousseau ihm eine Reihe autobiographischer Züge verlieh.

Doch ist in Jean-Jacques Rousseaus Briefroman die Lektüre das privilegierte Medium, das - wie sich hier, aber auch an vielen anderen Stellen zeigt - die Köpfe der jungen Mädchen verdreht und mit Liebesvorstellungen und Sehnsüchten füllt. Sie tut dies freilich in einer ständischen Gesellschaft, welche so depraviert ist, dass sie Romane und insbesondere Liebesromane benötigt, um ein wenig Zerstreuung und Nervenkitzel zu empfinden. Unverkennbar aber ist die Tatsache, dass sich die beiden Liebenden nun in einem anderen gesellschaftlichen und historischen Kontext bewegen, dass wir es also mit einer Art Modernisierung und Readaptation der legendären Liebenden des Mittelalters zu tun haben. Dabei besitzt die Geschichte - wie wir schon wissen - ihren historischen Kern. Rousseau hat damit das mittelalterliche Liebespaar in seine zeitgenössische Gegenwart übersetzt und die Normen, gegen welche einst Héloïse und Abélard aufbegehrten, in die gesellschaftlichen Ständeschranken seiner Zeit, des Jahrhunderts der Aufklärung übertragen. Der Genfer Bürger hat seine Liebesgeschichte mit viel Aufbegehren und mit viel durchaus sozialrevolutionärer Gesellschaftskritik gewürzt. ,Ma non troppo“, um das Lesevergnügen einer adeligen Leserschaft, die durchaus bereit war, sich auf Gedankenspiele und Experimente einzulassen, nicht entscheidend zu trüben.

Zentral musste aber die Liebesgeschichte sein. Vor diesem Hintergrund verwundert es uns selbstverständlich nicht länger, dass es im vierundfünfzigsten Brief - wiederum von Saint-Preux an Julie - den lange erwarteten Bericht von der geradezu unvermeidlichen Liebesnacht gibt und daher der Liebesvollzug

32 Vgl. hierzu Bronfen, Elisabeth: Nur über ihre Leiche. Tod, Weiblichkeit und Ästhetik. München: Deutscher Taschenbuch Verlag 1994; sowie (dies., Hg.): Die schöne Leiche. Weibliche Todesbilder in der Moderne. Wien: Goldmann 1992. 
gemeldet wird, der schon die beiden Liebenden des Mittelalters vereinte. Wie hätte Rousseau dieses nächtliche Schäferstündchen auch vermeiden können, orientierte er seine Leserschaft doch auch schon im Titel an jener Liebesgeschichte, die seinen Leserinnen und Lesern im 18. Jahrhundert bestens vertraut war.

Ich möchte Ihnen diese Passage nicht vorenthalten, zeigt sie doch auf, dass zumindest für einen Augenblick die Vereinigung des Liebespaares trotz aller gesellschaftlichen Grenzen und Schranken doch möglich war, während in der Folge dann die beiden Liebenden durch die Gesellschaft wieder auseinandergetrieben werden. Genießen wir also diese Szene, denn sie kommt nicht wieder:

Julie! So bin ich denn in Deinem Gemach, so bin ich denn im Heiligtum all dessen, was mein Herz anbetet. Die Fackel der Liebe leitete meine Schritte, und ich glitt hinein, ohne dass man mich gesehen hätte. Oh reizender Ort, glückseliger Ort, der Du einstens so viele zärtliche Blicke unterdrückt, so viele brennende Seufzer erstickt gesehen hattest: Du, der Du meine ersten feurigen Gefühle entstehen und sterben sahst, zum zweiten Mal wirst Du sie nun gekrönt sehen: Du Zeuge meiner unsterblichen Beständigkeit, sei nun der Zeuge meines Glückes und verschleiere für immer die Lüste des treuesten und des glücklichsten der Menschen.

Wie dieser mysteriöse Aufenthalt doch reizend ist! Alles schmeichelt und nährt die Glut, die mich verschlingt. Oh Julie! Er ist voll von Dir, und die Flamme meiner Begehren breitet sich über all Deine Spuren aus: Ja, alle meine Sinne sind zum gleichen Zeitpunkt trunken. Ich weiß nicht welcher unmerkliche Duft, süßer noch als die Rose und leichter als die Iris, hier all überall geatmet wird, ich glaube, hier den schmeichelnden Klang Deiner Stimme zu hören. Alle verstreuten Bestandteile Deiner Bekleidung zeigen meiner brennenden Einbildungskraft all jene Dinge von Dir selbst, die sie umhüllen: diese leichte Haartracht, von langen blonden Haaren geschmückt, die sie doch zu verdecken vorgeben; dieser glückliche Stofffetzen, gegen den ich ein einziges Mal zumindest nicht anzumurren brauche; dieses elegante und einfache Negligé, das so trefflich den guten Geschmack jener Frau wiederspiegelt, die es trägt; diese allerliebsten Pantöffelchen, die ein geschmeidiger Fuß so mühelos füllt; dieser von seinen Fesseln befreite Körper, der berührt und küssend umfängt ... Welch bezaubernde Taille! Obenan zwei leichte Konturen ... Oh Schauspiel der Wollust! ... Die Stangen des Korsetts sind unter der Kraft des Druckes gewichen ... Deliziöse Formen, die ich Euch tausendfach küsse! Ihr Götter, Götter, was wird sein, wenn ... Ah! Ich vermeine schon dieses zärtliche Herz unter einer glücklichen Hand schlagen zu spüren! Ah, Julie, meine charmante Julie! Ich sehe Dich, ich spüre Dich überall, ich atme Dich mit der Luft ein, die Du geatmet; Du durchdringst meine gesamte Substanz; wie ist das Zusammensein mit Dir brennend und schmerzhaft für mich! Wie schrecklich ist dies für meine Ungeduld! Oh komme, fliege, oder ich bin verloren.

Welch ein Glück, Tinte und Papier gefunden zu haben! Ich bringe zum Ausdruck, was ich fühle, um das Übermaß zu bändigen; ich halte meine Gefühlsbewegungen im Zaume, indem ich sie beschreibe.

Mir scheint, ich hörte Lärm: Sollte dies Dein barbarischer Vater sein? [...] 
Oh!, sterben wir, meine süße Freundin! Sterben wir, oh Du Geliebte meines Herzens! Was sollen wir fortan mit einer schalen, faden Jugend anfangen, deren Wonnen wir sämtlich gekostet? ${ }^{33}$

So also sieht die Beschreibung einer auf den Höhepunkt zutreibenden Vereinigung beider Liebender in der Zeit der Aufklärung aus! Wir erleben in dieser Passage sozusagen Schritt für Schritt die Annäherung, die Berührung, die wechselseitigen Durchdringungen der beiden Liebenden in einem Setting des 18. Jahrhunderts nach. Glücklicherweise hatte Saint-Preux - wie er auch schreibt - sogleich Papier und Feder bereit, um seine Leserschaft nacherlebend an diesem erotischen Höhepunkt teilnehmen zu lassen. Es ist dieses Erlebenswissen, das die Literatur uns zugänglich macht und uns als Nacherlebenswissen durch die Lektüre, durch das Lesen offeriert. Gewiss, die Sprache mag uns ferne sein, aber die Gefühle doch nicht. Denn wir können mit dem Liebenden uns langsam der Liebenden nähern und aus einer männlich determinierten Perspektive den weiblichen Körper in seiner Entschleierung unter dem männlichen Blick, unter dem Druck der männlichen Hände sehen. Dabei erscheint dieser weibliche Körper zunächst in den Formen der Kleidungsstücke, denen er seine Konturen aufprägte, bevor er für Saint-Preux hand-greiflich wird - ein gelungenes literarisches Verzögerungsspiel, das zugleich die Figura der Geliebten zum Vorschein bringt. Welch anderes Medium als die Literatur wäre in der Lage, diese Empfindungen während einer Liebesszene im Jahrhundert der Aufklärung uns so unmittelbar vor Augen zu führen, uns einen Eindruck von der Gefühlswelt zu geben, welche die Liebe im 18. Jahrhundert hervorrief und bedeutete! Der Roman lässt uns in Form von unmittelbar verfassten Briefen fast hautnah an den Ereignissen teilhaben.

Und selbst die Unterbrechung der Liebesszene ist Programm: Keine erste Liebesnacht ohne die Gefahr der plötzlichen Entdeckung! Es verwundert uns keineswegs, dass auch hier eine paternalistische Figur - in diesem Falle anders als bei Abélard und Héloïse nicht der Onkel, sondern der Vater selbst - als bedrohliche Gefahr evoziert wird und näher kommt. Es ist ein Vater, an dessen Stelle bald schon de Wolmar treten und den Liebenden von der Liebenden abtrennen und ins Abseits stellen wird. Aber immerhin: Saint-Preux hat sich unsterblich mit seiner Julie vereinigt und wird diese zärtliche Erfahrung nie mehr in seinem Leben vergessen. Die nachfolgende symbolische Kastration des liebenden männlichen Subjekts: Sie erscheint noch nicht am Horizont der selig miteinander Vereinten. Lassen wir die beiden Liebenden ihre einzigartige, aber auch einzige literarische Vereinigung genießen!

33 Rousseau, Jean-Jacques: Julie ou la Nouvelle Héloïse, S. $71 \mathrm{f}$. 
Denn der erotische Augenblick ist selbstverständlich ein literarischer Augenblick. Von großer Wichtigkeit ist in diesem Zusammenhang die Verbindung zwischen Liebe und Schreiben bezüglich einer Liebe, die nicht nur in der Lektüre verwurzelt und verankert ist, sondern zugleich auch zum Schreiben drängt. Die obige Passage macht deutlich, wie eng das Schreiben mit der Liebe verbunden ist und über das LiebeSchreiben vor allem auch die Gefühlswelt des Verfassers Einfluss nimmt. Ist die Liebe des Saint-Preux, ist die Liebe der Julie ohne das Schreiben und die wechselseitige Durchdringung in den gegenseitigen Briefen durch die Lektüre überhaupt vorstellbar? Das Schreiben enthält hier ein Lebenswissen und auch ein Überlebenswissen, denn nur so scheint sich Saint-Preux der Gefahr zu entziehen, die Spannung nicht mehr ertragen zu können, die durch seine Liebe zu Julie d'Etange entstanden ist. Insofern erfüllt das Schreiben wie auch das Lesen des Schreibens einen unmittelbar therapeutischen Zweck, der zugleich die Liebe der beiden Liebenden verlängert und letztlich - dank der Tätigkeit des Schriftstellers, der lediglich der Herausgeber dieser Briefe zu sein vorgibt - unsterblich macht.

Wie aber ist dieses Schreiben von der Liebe, dieses Schreiben über die Liebe beschaffen? Was sind die Ausdrucksformen, welches die rhetorischen Figuren, welche dieses Schreiben aus der unmittelbaren Erfahrung, aus dem unmittelbaren Erleben der Liebe prägen? Die Antwort auf diese Fragen ist schnell gegeben und ich will Sie nicht auf die Folter spannen: Asyndeton, Katachrese, Agrammatikalität, Eine Vielzahl von Interjektionen und alogischer Perioden führen jene Verwirrungen der Sinne und der geistigen Fähigkeiten vor, die von der Liebe und vom Verliebt-Sein beim Liebenden ausgelöst werden. Logische Kognition ist in der Liebesvereinigung nicht angesagt, denn das liebende Subjekt kann sich seiner nicht mehr sicher sein und drückt dies auch sprachlich aus: Seine Gefühle durchdringen alles!

Die erste Liebesnacht mit Julie, die auch die letzte bleiben soll, ist noch vom Stoff, noch vom Schleier bedroht; doch dieser zerreißt - und auch hier ist dies bis hinein in die Körperlichkeit der Liebenden nachvollziehbar, wird damit doch der Vorgang der Entjungferung angedeutet. Doch die Durchstoßung des Jungfernhäutchens, des Hymen, räumt letztlich nicht das Hindernis, das „obstacle“ beiseite, das den Liebenden wie die Liebende von ihrer Erfüllung trennt. Endgültige Klarheit tritt nicht ein, da der Schleier, der die ersehnte Transparenz aller Dinge bedeckt, nicht verschwunden ist. Es wird nur kurze Zeit vergehen, bis dieser „voile“ wieder in anderer Form zwischen Liebendem und Liebender auftauchen wird. Zugleich wird von Beginn an deutlich, dass wir es hier unverkennbar mit der Resakralisierung des Profanen, mit der Heiligsprechung des Objekts einer Liebe zu tun haben, die den Liebenden gleichsam in einen Anbetenden angesichts der von ihm vergötterten Frau verwandelt. Nicht umsonst be- 
dient sich Saint-Preux des Verbums „adorer“: Die Angebetete wird in ihrem Tempel verehrt und geliebt.

Entscheidend aber ist die massive und zugleich ausdifferenzierte Sinnlichkeit dieser Passage, in der die einzelnen Sinne angesprochen, zugleich aber auch Synästhesien entfaltet werden, welche alle Sinne wieder miteinander verquicken. Auch das „je ne sais quoi“ darf hier nicht fehlen, jener Restbestand des Irrationalen, der in diesem Zitat im Verbund mit den Düften, die am weitesten in die Kindheit als Erinnerungsspuren zurückreichen, genannt wird. ${ }^{34}$ JeanJacques Rousseau bietet alle literarischen und rhetorischen Mittel auf, um seiner Leserschaft die Atemlosigkeit und den Höhepunkt dieses Liebes-Augenblicks literarisch adäquat zu vermitteln.

Und immer wieder ist es die Metaphorik des Feuers, das brennende Begehren und die in Brand gesteckte Imagination, welche den Liebenden mit all seinen „feux“ vorwärtstreiben und schließlich auch den Körper Julies - in einem Brief an Julie selbst, die sich gleichsam in der literarischen Pupille wie in einem Spiegel betrachten kann - in all seinen Einzelheiten erfassen, darstellen und berühren. Die weibliche Körperlichkeit erscheint leibhaftig, in ihrer konkreten wie in ihrer symbolischen Form, gleich zweifach vor der Sinneswahrnehmung des männlichen Liebenden. Denn an dieser Stelle taucht auch das menschliche Herz in seiner konkreten Form gleichsam als weibliche Brust in der - wie es in diesem Zitat des Liebenden heißt - „glücklichen“ Hand des männlichen Geliebten auf: als Körperform und als Sitz der überwältigten Gefühle. Die einzelnen Teile des weiblichen Körpers werden personifiziert und gewinnen unter dem männlichen Blick, unter der männlichen Hand gleichsam ein Eigenleben. Die Ver-Körperung Julies ist geschlechterspezifisch determiniert und führt uns vor Augen, dass die Orchestrierung dieses Briefromans diejenige eines männlichen heterosexuellen Schriftstellers ist.

So also wird ein Spektakel der Wollust im 18. Jahrhundert in Szene gesetzt! Julie ou la Nouvelle Hélö̈se wurde nicht umsonst zu einem Bestseller des Aufklärungszeitalters. Die Inszenierung des Erotischen erfolgte mit Hilfe all jener literarischen Verfahren, über die Rousseau bereits in Perfektion verfügte und die im Grunde über eine lange Traditionslinie der Romantik hindurch präsent sein werden. Und doch ist selbst noch im Liebesgenuss, in der „volupté“, doch immer der Schmerz, der brennende Schmerz des Liebenden präsent: Nichts kann ihn tilgen oder vergessen machen, ihm kann sich das liebende Subjekt nicht entziehen!

34 Zur Bedeutung des „Je ne sais quoi“ vgl. die erhellende Studie von Köhler, Erich: „Je ne sais quoi“. Ein Kapitel aus der Begriffsgeschichte des Unbegreiflichen. In (ders.): Esprit und arkadische Freiheit. Aufsätze aus der Welt der Romania. Frankfurt am Main: Klostermann 1966, S. 230 ff. 
Auch dies gehört zweifellos in das Umfeld der Liebestheorie von Denis de Rougemont, ${ }^{35}$ der seinen Genfer Uhrmachersohn sehr gut kannte und wusste, aus welchen kulturellen und religiösen Quellen Jean-Jacques Rousseau schöpfte.

Im Grunde wird der Liebende erst so die Authentisierung seiner Leidenschaft, seiner Passion, an sich selbst erfahren können. Und im Grunde wird erst diese Dimension geteilter Leidenschaft und geteilten Leidens später erklären, wieso es am Ende mit dem Tod Julie de Wolmars doch noch zu der zuvor immer wieder abgewendeten Katastrophe kommt. Der Liebesroman von Jean-Jacques Rousseau hat kein Happy Ending und kann auch keines haben. Denn schon am Ende des obigen Zitats, das eigentlich den Beginn des nachfolgenden und überaus interessanten Briefes darstellt, zeigt sich, dass nun bereits der Tod am Horizont erschienen ist. Denn die Lust ist genossen, die Wollust ein erstes Mal befriedigt: Alles andere kann nun nur noch ein vergeblicher Kampf gegen die gesellschaftlichen Kräfte und - vielleicht schlimmer noch - immer nur die Wiederholung dieser so stürmisch und leidenschaftlich ersehnten „délices“, dieser Wonnen, sein. So enthält der Liebesvollzug sozusagen in nuce nicht nur den kleinen, sondern auch den großen Tod. Ein permanentes, dauerhaftes Glück ist für den Menschen - wie Rousseau später in seinen Rêveries du promeneur solitaire schrieb - hienieden nicht erreichbar.

Die stets ersehnte Liebe wird in der Konstellation, die von Rousseau in seinem Briefroman entfaltet wird, zum eigentlichen Konstituens des Individuums, zu jener Kraft, die das moderne Subjekt überhaupt erst konstituiert und ausmacht. Denn in die Liebe gehen all jene Aspekte moderner Subjektivität - einschließlich der Einzigartigkeit des Subjekt wie auch der Einzigartigkeit seines Objekts - ein, so dass die Gefühle der Liebe fortan zu einem Gradmesser des modernen Subjekts in einer sich zunehmend verbürgerlichenden Welt des ausgehenden 18. Jahrhunderts werden. Sag' mir, wie Du liebst, und ich sage Dir, wer Du bist!

Dies wird in einem langen Brief des zweiten Teils, dem elften Brief von Julie an Saint-Preux, deutlich, stellt die schöne Julie doch jene Frage, die natürlich für viele Romanfiguren mehr als vital ist: Was wären wir noch ohne die Liebe? Was wäre ein Liebespaar, das der Liebe verlustig gegangen wäre?

Mein Freund, man kann auch ohne Liebe die erhabenen Gefühle einer starken Seele empfinden: Aber eine Liebe so wie die unsrige belebt und erhält sie solange sie brennt; sobald sie erlöscht, verfällt sie in Lähmung, und ein verbrauchtes Herz ist zu nichts mehr nutze. Sage mir, was wir wären, wenn wir uns nicht mehr liebten? Nun? Wäre es da nicht besser, nicht länger zu sein, als zu existieren, ohne etwas zu fühlen, und könntest Du Dich dazu durchringen, auf der Erde umher zu wandeln und das abgeschmackte Leben eines gewöhnlichen Menschen zu führen, nachdem Du alle Gefühlsbewegungen gekostet, die

35 Vgl. Rougemont, Denis de: L'Amour et l'Occident. Paris 1939. 
eine menschliche Seele verzaubern können? [...] Ich weiß nicht, ob Du woanders das Herz von Julie wiederfinden würdest; aber ich fordere Dich heraus, jemals bei einer anderen zu fühlen, was Du bei ihr gefühlt’. Die Erschöpfung Deiner Seele wird Dir das Schicksal ankündigen, das ich Dir vorhergesagt; Traurigkeit und Überdruss werden Dich im Schoße Deiner frivolen Amüsements niederstrecken; die Erinnerung an unsere erste Liebe wird Dich Dir zum Trotze verfolgen; mein Bildnis, hundertmal schöner als ich es jemals war, wird Dich urplötzlich überkommen. Und sofort wird der Schleier der Abscheu all Deine Lüste bedecken, und tausendfaches bitteres Bedauern wird in Deinem Herzen wach werden. Mein Geliebter, mein süßer Freund, ah! Solltest Du mich je vergessen ... Oh weh, ich könnte daran nur sterben; aber Du würdest gemein und unglücklich leben, und ich wäre im Sterben nur zu gut gerächt. ${ }^{36}$

Über Julies ,liebevollem‘ Diskurs stehen die Einzigartigkeit des Liebenden Subjekts und die Einzigartigkeit des geliebten Objekts, die Unverwechselbarkeit und Unwiederholbarkeit einer Liebe, die niemals von anderen Subjekten, die niemals mit anderen Objekten wiederholt werden kann. Daraus ergeben sich die Drohungen der liebenden Frau, diese Liebe niemals aufzugeben, niemals für eine andere einzutauschen, weil sie einzigartig ist und niemals hintergangen werden kann. Denn für diesen Fall droht sie dem männlichen Subjekt mit Vergeltung und Rache: Ein Schleier werde sich für immer zwischen ihn und alle anderen Vergnügungen und Lüste legen, sollte Saint-Preux seiner Julie irgendwann einmal untreu werden.

Was sind dies für liebevoll geäußerte herzensliebe Drohungen! Und welche Verfluchung des Liebespartners ist diese liebevolle, zärtliche Umarmung, in der sich noch die Verwünschung all seiner Tage, die er auf Erden ohne sie verbrächte, äußert! In dieser Passage wird deutlich, wie sehr die Konstruktion der eigenen Subjektivität an der Konstruktion des Ich als liebendem Subjekt ausgerichtet ist. Die Gattung des Briefromans ermöglicht es, die Perspektiven zu wechseln und damit auch die Sichtweise einer liebenden Frau einzunehmen, die ihrem Geliebten gleichsam ihr allgegenwärtiges Bildnis zur raschen Bestrafung wünscht, sollte er sie jemals aus dem Blick verlieren. Julie wünscht ihrem Saint-Preux folglich nicht den Tod; aber über ihre eigene Leiche ${ }^{37}$ wünscht sie ihm ein ewiges Schmachten nach ihr, selbst und gerade in den Stunden der Lust mit einer anderen. Auch dies kann ein Diskurs, kann eine Sprache der Liebe sein: die Bilder des leidenden Anderen, der mir nach meinem Tode untreu geworden ist - ihm sei ewige Verdammnis beschieden! Denn in einem solchen Fall hätte er sich nicht allein an ihrer und an der gemeinsamen Liebe,

36 Rousseau, Jean-Jacques: Julie ou la Nouvelle Héloïse, S. 112.

37 Vgl. zu diesem Themenkomplex Bronfen, Elisabeth: Nur über ihre Leiche. Tod, Weiblichkeit und Ästhetik (1994). 
sondern an ihrem ganzen Wesen, an ihrem ganzen Sein als Subjekt vergangen. Man darf hier sehr wohl von einer Verfluchung sprechen.

Die Literatur transportiert ein Wissen vom Leben und ein Wissen vom Lieben, das zweifellos auch und gerade die Grenze zwischen Leben und Tod übersteigt. Denn - mit Nietzsche gesprochen - ,alle Lust will Ewigkeit, will [...] tiefe, tiefe Ewigkeit““. ${ }^{38}$ Das Wissen über die Liebe und deren Vision bestimmen das Wissen über ein Leben, das es zu führen, aber auch über ein Leben, das es zu vermeiden gilt. Denn selbst das Leben nach dem Tod des Liebespartners muss noch immer im Zeichen dieses verstorbenen geliebten Menschen stehen.

Dies ist ein Lebenswissen, das sich gegen das „ordinaire“ richtet, gegen das gewöhnliche bürgerliche Leben, gegen ein Leben ohne Passion, ohne diese Einzigartigkeit des unverwechselbaren Individuums, das nur von und durch die Liebe garantiert wird. Es sind durchaus gewalttätige Metaphern, die Julie ihrem geliebten Saint-Preux da schreibt. Es ist ein Lebenswissen und ein Liebeswissen, das sich gegen die Norm, gegen die Konventionen, gegen die Gewohnheiten der Masse richtet, um eine eigene, unverwechselbare Form der Liebe und des Lebens zu errichten. Die Abgrenzung von allen anderen ist für das moderne Subjekt auch in der Liebe konstitutiv. Liebe strebt nicht allein nach Ewigkeit: Sie will auch vollumfängliche Einmaligkeit und Unwiederholbarkeit, zumindest in ihrer absoluten Lebens- und Liebesform. Das moderne Subjekt fordert Liebe und Anerkennung bis weit über den Tod hinaus.

Dieser Liebesschwur und die Liebesbeschwörung von Julie d'Etange bilden eine Aussage, die auf den ersten Blick in Kontrast und Konflikt mit der erzwungenen Vernunftehe mit de Wolmar und deren Akzeptanz durch die junge Frau wie ihren bürgerlichen Liebhaber zu stehen scheint. Denn war Julie nicht eine Vernunftehe mit einem vernünftigen Adeligen eingegangen und hatte ihren Saint-Preux damit hintergangen? Hätte sie nicht mit ihm fliehen, unerkannt in irgendeinem Alpendorf, in irgendeiner Großstadt leben können - stets ihrer gemeinsamen Liebe treu?

Doch die Ehe mit einem klugen Patriarchen, der Saint-Preux' Gegenwart aus guten Gründen toleriert, vermag die ewige Liebe der Julie nicht auszulöschen. Gerade die finale Katastrophe des Untergangs von Julie de Wolmar zeigt, dass in Julie d'Etange letztlich doch die fortbestehende, unverändert liebende Julie als Nouvelle Héloïse, als neue Héloïse des 18. Jahrhunderts, zu erblicken ist. Ihre Gesellschaftsutopie von Clarens wirkt aus dieser Perspektive wie das Kloster von Heloïse, eine Gemeinschaft von Gleichdenkenden, die doch letztlich nie die Passion für und mit dem anderen, mit der einzigen und niemals

38 Nietzsche, Friedrich: Das andere Tanzlied. In (ders.): Werke in vier Bänden, Bd. 4, S. 286. 
ersetzbaren Liebe, substituieren können. Denn die Gemeinschaft der Gleichgesinnten tröstet, kann aber die individuelle Liebe des Liebespaares niemals ersetzen. Denn letztere ist einzigartig und schließt alle anderen aus dieser heterosexuellen Zweiergemeinschaft aus. Mag sein, dass Julie inmitten ihres Lebens mit de Wolmar das erschien, was sie auf Saint-Preux projizierte: Das Bildnis ihres Liebhabers, das sie noch in alle Stunden der Intimität hinein verfolgte. Mag sein, dass sie selbst so litt, wie sie es ihrem Saint-Preux androhte!

Freilich zeigt sich in dieser Passage nicht nur der absolute Liebesanspruch des liebenden Subjekts sowie die geradezu existenzgefährdende Weise, mit welcher dem Liebespartner gleichsam eine „malédiction“ nachgeschleudert wird, falls er oder sie das geliebte Objekt je vergessen und sich in den Armen einer oder eines anderen wiederfinden sollte. Wir haben hier noch immer das „amabam amare“ des Augustinus, jene feine Beobachtung von Denis de Rougemont, dass in der Passion von Tristan und Isolde eben jene Liebe zum eigenen Ich, die Liebe zum Ich als Liebendem oder Liebender, immer wieder die Oberhand gewinnt. Doch es ist ein „amabam amare“, das in der Take-off-Phase der Moderne in die Bedingungen moderner Subjektivität übersetzt worden ist. Vergessen wir diese Selbstliebe also nicht in der Liebesbeziehung zwischen beiden Liebenden am Genfer See: Sie bildet ganz zweifellos eine wichtige Komponente, die gerade auch in der sanften, liebevollen Verfluchung des Anderen zu Tage tritt! Diese Verfluchung des (sich) liebenden Subjekts und die unverbrüchliche Liebe gehören zusammen.

Doch just in diesem Kontext wird die Ich-Konstruktion von der Liebe geleitet, so dass nicht verwundern kann, dass der Andere paradoxerweise letztlich doch immer außerhalb dieser Konstruktion des Subjekts bleibt. Das geliebte Objekt ist dabei zunächst einmal völlig gleichgültig, wird auch noch so oft und so vehement Anspruch auf dieses „objet“ von der oder dem Liebenden erhoben. Die Einzigartigkeit des Subjekts erweist sich in der Einzigartigkeit seiner Liebe, die allein sie oder ihn davor sichert, in den Bereich des Gewöhnlichen, des Normalen, ja des ordinären zurückzufallen und damit die eigene Größe und Unverwechselbarkeit aufzugeben. Stets schwingt das „amabam amare“ bei der Subjektkonstruktion mit: Es zielt auf die Größe und Unverwechselbarkeit eines modernen Subjekts, das sich ruhelos selbst befragt und hinterfragt, aber an seiner eigenen Individualität und Einzigartigkeit nicht zweifeln kann, nicht zweifeln darf.

Genau an dieser Stelle aber findet sich die tiefe Beziehung zu Rousseaus Les Confessions, zur Konstruktion der Subjektivität als Abgrenzung von allen anderen, ohne den Anspruch aufzugeben, doch für alle anderen stehen und 
verstehen zu können: „Je sens mon cœur et je connais les hommes“, hieß es gleich zu Beginn jener Bekenntnisse. In dieser Hinsicht ist die Liebe das zentrale Konstruktionselement des Lebens; das Wissen über die Liebe ist damit ein Wissen über das Leben und letztlich auch über die Möglichkeiten und Unmöglichkeiten des Überlebens - und eben hierin wird das Wissen um Liebe auch zu einem Überlebenswissen, das Julie de Wolmar nicht im ausreichenden Maße zur Verfügung steht. So kann auch Rousseaus Liebesgeschichte - im Wissen um die von Elisabeth Bronfen herausgearbeiteten Zusammenhänge zwischen Tod, Weiblichkeit und Ästhetik - nur über ihre Leiche, nur über den Tod der weiblichen Protagonistin, verhandelt werden. Julie wird so trotz allem doch noch zur tragischen Figur, tragischer als ihr stets in sich verhakter Saint-Preux.

Wie bei Héloïse und Abélard, aber auch wie bei Tristan und Isolde bringt erst der Tod die wahre Vereinigung, auf die die Vereinigung im Leben nur ein erster Vorgeschmack, ein vorübergehender Augenblick war. Die Vereinigung im Tod ist das, was die moderne Subjektivität über den Tod hinaus in die Ewigkeit projiziert. Der kleine Tod geht stets dem großen Tod voraus. Doch in der geschlechtlichen Vereinigung - im Liebesakt also - ruht freilich immer ein Versprechen von Ewigkeit und von unverbrüchlicher Passion. Dieses Versprechen aber gilt nicht für die christliche Liebe, nicht für das Sakrament der christlichen Ehe, die in Clarens, in Julie ou la Nouvelle Hélöise als Gegenbild entworfen wird - und zwar als ein Gegenbild in fast vollständiger Perfektion. Denn die Ehe mit dem älteren und adeligen de Wolmar steht für diese Konzeption, aber letztlich auch für deren Scheitern ein. Die ideale Gemeinschaft von Clarens kann die Liebe der „Neuen Héloïse“ zu Saint-Preux nicht überstrahlen: Im Angesicht dieser Liebe tritt sie in den Schatten des Vernünftigen, ja des Ordinären.

Denn es ist die gegen die gesellschaftlichen Normen, gegen die Ständegrenzen des Ancien Régime, gegen die Konventionen, gegen die Gebote der Kirche gelebte Leidenschaft, welche seit dem Mittelalter als dauerhafte Strömung nachweisbar nun in der Vorromantik und der Empfindsamkeit mit einer ungeheuren Kraft hervorbricht und alles mitzureißen scheint, was sich alledem entgegenstellt. Genau an dieser Stelle brechen sich die sozialrevolutionären Implikationen der Vorstellungswelt Rousseaus Bahn, wird die Liebe also zum experimentellen Labor einer Gesellschaft, die in dieser Form nicht länger Bestand haben wird. Denn dieses auf der feudalen Ständeordnung basierende Gesellschaftssystem wird nicht länger die Form bilden können, in welcher sich die moderne Subjektivität entfaltet. So wie die festgefügte Ordnung eines europäischen Wissens, das sich selbst ins Zentrum aller Erkenntnis und später allen Fortschritts setzt, nicht länger jenem Drucke standhalten wird, wel- 
cher in einer beschleunigt zusammenrückenden Welt von den Philosophen wie den Wissensbeständen der außereuropäischen Welt ausgeübt werden wird. Die zweite Hälfte des 18. Jahrhunderts steht ganz im Zeichen dieser Umwälzungen, die in erster Linie Umwälzungen des Wissens sind - einschließlich des Lebenswissens. 